\title{
Types of Co-existing Chronic Physical Conditions and Newly- diagnosed Depression, its Treatment and Economic Outcomes among Medicaid Beneficiaries with Type 2 Diabetes
}

Rituparna Bhattacharya

Follow this and additional works at: https://researchrepository.wvu.edu/etd

\section{Recommended Citation}

Bhattacharya, Rituparna, "Types of Co-existing Chronic Physical Conditions and Newly-diagnosed Depression, its Treatment and Economic Outcomes among Medicaid Beneficiaries with Type 2 Diabetes" (2015). Graduate Theses, Dissertations, and Problem Reports. 5206.

https://researchrepository.wvu.edu/etd/5206

This Dissertation is protected by copyright and/or related rights. It has been brought to you by the The Research Repository @ WVU with permission from the rights-holder(s). You are free to use this Dissertation in any way that is permitted by the copyright and related rights legislation that applies to your use. For other uses you must obtain permission from the rights-holder(s) directly, unless additional rights are indicated by a Creative Commons license in the record and/ or on the work itself. This Dissertation has been accepted for inclusion in WVU Graduate Theses, Dissertations, and Problem Reports collection by an authorized administrator of The Research Repository @ WVU.

For more information, please contact researchrepository@mail.wvu.edu. 
Evolution of a Disintegrin and Metalloproteinase Gene Family in Vertebrates

Shashwati Bhattacharya

Thesis submitted to the

Eberly College of Arts and Sciences

at West Virginia University

in partial fulfillment of the requirements

for the degree of

Master of Science

in

Biology

Dr. Shuo Wei, Ph.D., Chair

Dr. Jennifer Hawkins, Ph.D.

Dr. Clifton Bishop, Ph.D.

Department of Biology

Morgantown, West Virginia

2015

Keywords: ADAM; testicular ADAMs; tandem duplication; retroposition.

Copyright 2015 Shashwati Bhattacharya 


\section{ABSTRACT}

\section{Evolution of a Disintegrin and Metalloproteinase Gene Family in Vertebrates}

\section{Shashwati Bhattacharya}

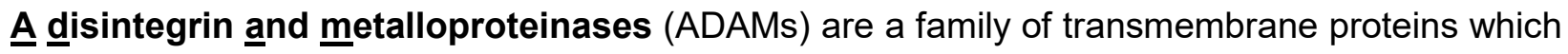
have diverse functions in various tissues. They play important roles in cellular and developmental processes and are present in various species. ADAMs are classified according to their expression in tissues into the somatic ADAMs (sADAMs) and the testicular ADAMs (tADAMs). The sADAMs are expressed in somatic tissues, and the testicular ADAMs (tADAMs) are expressed predominantly in the testis. The tADAMs are further classified into Group I and Group II, based on the absence or presence of introns. The mechanism of evolution of the tADAMs was unknown. Using bioinformatics tools, we performed an analysis of the evolution of ADAM genes in various vertebrates from fish to mammals. Our results show the duplication and loss of tADAMs in certain vertebrate species. In our phylogenetic analysis, all the tADAMs cluster together with ADAM9 and ADAM9-like, which we identified as a close paralog of ADAM9 in certain non-mammalian vertebrates, but are more distantly related to other sADAMs. Our synteny analysis shows that most Group II tADAMs lie next to the Adam 9 gene locus and hence likely arose from tandem duplication. On the other hand, Group I tADAMs are intronless, so they likely originated through retroposition. Therefore, we hypothesize that ADAM9/9-like and the tADAM loci are hotspots of gene duplication because many events of tandem duplication and retroposition have occurred in these regions. Some tADAMs were pseudogenized in certain species as a result of duplication events. The rapid duplication of ADAM genes resulted in diverse functions of ADAMs in various species and hence contributed to the evolution of species. 


\section{ACKNOWLEDGEMENTS}

I would like to first thank my advisor, Dr. Shuo Wei, for his guidance and support throughout the years, and for being there for me both professionally and personally. Without your leadership and encouragement I would not have developed as much as a scientist. Secondly, I would like to thank the members of my committee, Dr. Clifton Bishop and Dr. Jennifer Hawkins for all of their direction and assistance.

I would also like to pay special thanks to our postdoctoral fellow Dr. Harinathachary Bahudhanapati, who graciously helped me organize the project.

I would like to thank the present members of my lab: Mark Perfetto, Dr. Laura Christian, and Tyler Koch for their suggestions to improve.

In addition, I would like to thank all faculty, staff, and graduate students from the Department of Biology at West Virginia University.

Most importantly, I would like to thank my parents Mr. Subinoy Bhattacharya and Mrs. Manjari Bhattacharya, and my sister. I am thankful to my husband Mr. Agniva Banerjee for his support and encouragement. I am grateful for all the support and love you have given me throughout the years and for always believing in me. Your encouragement and patience has allowed this to be possible. I am grateful to my in-laws for being supportive. 
Table of Contents

\begin{tabular}{|c|c|c|}
\hline & ABSTRACT & ii \\
\hline & ACKNOWLEDGEMENTS & iii \\
\hline & List of tables & $\mathrm{V}$ \\
\hline & List of figure & vi \\
\hline 1. & INTRODUCTION & 1 \\
\hline 1.1. & Background & 1 \\
\hline 1.2. & Structure of ADAMs & 3 \\
\hline 1.3. & Functions of ADAMs & 4 \\
\hline 1.4. & Classification of tADAMs & 5 \\
\hline 1.5 . & Key roles of ADAMs in fertilization & 5 \\
\hline 1.6. & Objectives & 7 \\
\hline 1.7. & Significance of the study & 7 \\
\hline 2. & MATERIALS AND METHODS & 7 \\
\hline 2.1. & Identification of Adam genes in tested vertebrate species & 7 \\
\hline 2.2 . & Phylogenetic analyses & 8 \\
\hline 2.3 . & Syntenic analyses & 10 \\
\hline 2.4 . & Identification of retroposition event among the ADAM genes & 11 \\
\hline 3. & RESULTS & 11 \\
\hline 3.1. & TADAMs in various animal species & 11 \\
\hline 3.2 . & Story of ADAM9 and ADAM9-like & 11 \\
\hline 3.3 . & $\begin{array}{l}\text { Group I and Group II tADAMs cluster with ADAMs } 9 \text { and } 9 \text {-like forming a } \\
\text { subfamily }\end{array}$ & 12 \\
\hline 3.4 . & Evolution of Group II tAdam genes & 13 \\
\hline 3.5 & Evolution of Groupl tAdam genes: evidence for retroposition & 14 \\
\hline 3.6. & A recent event of retroposition & 15 \\
\hline 3.7. & Tandem duplication of Group I tAdams & 15 \\
\hline 4. & DISCUSSION & 16 \\
\hline 5. & CONCLUSION & 17 \\
\hline & REFERENCES & 33 \\
\hline & APPENDIXI & 41 \\
\hline
\end{tabular}




\section{LIST OF TABLES}

1. Classification of mouse tADAMs.

2. Accession numbers of ADAM proteins used in phylogenetic trees.

3. Expression of ADAM9 and Group II tADAMs transcripts in mouse and human. 


\section{LIST OF FIGURES}

Figure 1: Structure of ADAM. The domain structure comprises of SP (signal peptide), PRO (prodomain), MP (metalloproteinase domain), DIS (disintegrin domain), CRD (cysteine-rich domain), EGF (epidermal growth factor-like domain), TM (transmembrane region), and CT (cytoplasmic tail).

Figure 2: Bayesian trees of ADAMs for vertebrate species. Bayesian trees of ADAMs for frog (Xenopus tropicalis) (A), lizard (Anolis carolinensis) (B), chick (Gallus gallus) (C), opossum (Monodelphis domestica) (D), mouse (Mus musculus) (E) and human (Homo sapiens) (F) were generated using Mr. Bayes software.

Figure 3: Syntenic analyses of the Group II Adams. Most of the Group II tAdams lie next to Adam 9 in all vertebrates, except for Adam2 in rodents.

Figure 4: Syntenic analysis of Adam9-like gene. Syntenic analysis of Adam9-like copy from lower non-mammalian vertebrates to cartilaginous elephant shark showed that it is highly conserved, while it disappeared in the course of evolution in higher mammals.

Figure 5: Comparison between Adam9a and Adam9b of opossum. (A) Location of Adam 9a and $9 \mathrm{~b}$ in the opossum genome. (B) Comparison table of Adam9a and Adam9b of opossum. (C) The gene structure of Adam $9 b$. The Adam $9 b$ pseudogene contains a polyA sequence, and the only intron was identified as an opossum retroposon (Mdo3LTR1a/ERV1), which was likely inserted after the retroposition event that generated Adam9b. The structure of the Adam9a mRNA is shown. The black vertical lines in Adam9a mRNA represent splice sites (Courtesy of Dr. Hari Bahudhanapati). 
Figure 6: Adam1 duplication. Expansion of Adam1 through tandem duplication in chicken, opossum and mouse genome. Adam 1 gene is not found in the Xenopus tropicalis genome and only one copy was found in the Anolis genome.

\section{Appendix:}

Figure 1: Bayesian tree of ADAM9 for all tested vertebrates.

Figure 2: Maximum likelihood tree for human ADAMs.

Figure 3: Maximum likelihood tree for mouse ADAMs.

Figure 4: Maximum likelihood tree for opossum ADAMs.

Figure 5: Maximum likelihood tree for lizard ADAMs.

Figure 6: Maximum likelihood tree for chicken ADAMs.

Figure 7: Maximum likelihood tree for frog ADAMs.

Figure 8: Maximum likelihood tree of ADAM9 for all tested vertebrates.

Figure 9: Neighbor joining tree for human ADAMs.

Figure 10: Neighbor joining tree for mouse ADAMs.

Figure 11: Neighbor joining tree for opossum ADAMs.

Figure 12: Neighbor joining tree for lizard ADAMs.

Figure 13: Neighbor joining tree for chicken ADAMs.

Figure 14: Neighbor joining tree for frog ADAMs.

Figure 15: Neighbor joining tree of ADAM9 for all tested vertebrates. 


\section{INTRODUCTION}

\subsection{Background:}

The "A disintegrin and metalloproteinase" (ADAM) family of proteins play important roles in cellular and developmental processes. The first two members of the ADAM family were identified as guinea pig sperm-surface proteins that were recognized by the monoclonal antibody PH-30 (Primakoff et al., 1987). These sperm surface proteins from guinea pig were found to have a metalloproteinase-like and a disintegrin-like domain, and are related to the family of snake venom protein domains (Blobel et al., 1992; Wolfsberg et al., 1993). These proteins were therefore named ADAM for containing "A Disintegrin" and "A Metalloproteinase" domain (Wolfsberg et al., 1995).

ADAMs belong to the metzincin superfamily of proteases (Bode et al., 1996). This superfamily of proteases have a zinc binding consensus sequence HExxHxxGxxH that is present in all proteolytically active members (Stocker et al., 1995). Zinc-dependent proteases are classified into gluzincin, metzincin, inuzincin, carboxypeptidase, and DD carboxypeptidase subgroups according to the primary structure of their catalytic sites (Hooper NM. 1994). The ADAMs belong to the metzincin subgroup which is subdivided into serralysin, astacin, matrixin, and adamalysin (Stocker et al., 1995). The serralysins are a family of proteolytic enzymes that are secreted by various bacteria of genus Serratia (Nakahama et al., 1986). Astacins are proteases which are found in wide range of organisms and function in processing proteins (Bond et al., 1995). The matrixins comprise the matrix metalloproteinases (MMPs). Adamalysins, including ADAMs, have a metalloproteinase domain and a unique integrin receptor-binding disintegrin domain. 
ADAMs are mainly multi-domain type I transmembrane proteins. Some ADAMs can be present in a soluble form because of alternative splicing or protease-mediated cleavage. ADAMs are present in invertebrate species such as nematode Caenorhabditis elegans and all vertebrates. Adam-like sequences have been found in the yeast Saccharomyces pombe (Edwards et al., 2008).

ADAMs are involved in a variety of functions. In mammals, many of the ADAMs are expressed in somatic tissues, and are known to have a role in cell fate determination in the central nervous system, cell migration, as well as axon and muscle development (Primakoff et al., 2000). Functions of ADAMs vary from neural crest development in frogs and chicken, adipogenesis and myogenesis in mice, to the fusion of sperm and egg in mice (Rooke et al. 1996; Kurisaki et al., 2003; Cousin et al., 2011; Schiffmacher et al., 2014). The main functions of ADAMs are proteolysis, adhesion and intercellular signaling. Biological functions of many ADAMs are still unknown. ADAMs have been implicated in many diseases, including cancers, immune diseases and neurodegenerative diseases (Edwards et al., 2008). For example, ADAM9 is upregulated in many cancers and also spreads colon cancer cells by binding to integrins $\alpha 6 \beta 4$ and $\alpha 2 \beta 1$ (Edwards et al., 2008). Some ADAMs stimulate cell proliferation via EGFR receptor activation and cause growth of malignant tumors (Borroto et al., 2003; Kenny et al., 2007). On the other hand, ADAMs can also be used for therapeutics. For example, ADAM10 plays an important role in Alzheimer's disease by participating in non-amyloidogenic processing of amyloid-beta precursor protein (APP) and hence helps in alleviating the progress of the disease (Cong et al., 2009). Therefore, therapies can be developed by either promoting or inhibiting ADAM activities depending on the disease. 


\subsection{Structure of ADAMs:}

The basic structure of ADAMs consists of a signal peptide, a prodomain (PRO), a metalloproteinase domain (MP), a disintegrin domain (DIS), a cysteine-rich domain (CRD), a transmembrane region (TM) and a cytoplasmic tail (Figure 1). A signal peptide at the N-terminus of an ADAM directs it into the secretory pathway and the prodomain functions as a chaperone to facilitate the proper folding and secretion of ADAMs (Roghani et al., 1999). The prodomain also prevents self-cleavage by binding and inhibiting the MP domain. A "cysteine switch" in the prodomain of some ADAMs function to regulate the MP domain, and hence regulate proteolysis (Zhu et al., 1999, Brachvogel et al., 2003). Proprotein convertases cleave the prodomain in the Golgi, resulting in activation of ADAM proteases (Schlondorff et al., 1999). The MP domain in proteolytically active ADAMs contains a consensus sequence HExxHxxGxxH, which binds the catalytic zinc ion. The zinc ion is necessary for hydrolytic processing of protein substrates. A 'Met turn', i.e., a methionine residue C-terminal to this consensus sequence, stabilizes the zinc ion and maintains the structure of the active site (Seals et al., 2003). About half of the ADAMs lack this consensus sequence in the MP domain, and hence lack the protease activity (Brocker et al., 2009). The DIS domain has a disintegrin loop, which is responsible for the interaction with integrins (White, 2003). ADAMs, except for ADAM10 and ADAM17, have a Rx6DEVF sequence in their DIS domain which interacts with the $\alpha 9 \beta 1$ integrin (Eto et al., 2002). The CRD of ADAM12 is involved in cell-matrix adhesion by acting as a ligand for syndecan (a cell adhesion molecule) (Seals et al., 2003). The CRD of Xenopus ADAM13 has been shown to interact with the glycoprotein fibronectin (Gaultier et al., 2002). The cytoplasmic tail varies in length among various ADAMs, and may contain binding sites for different proteins (Cho, 2012). Several ADAMs have one or more PXXP sites for binding to $\mathrm{SH} 3$ motif-containing proteins, which interact with various intracellular proteins. For example, the cytoplasmic tail of ADAM12 
interacts with alpha-actinin2, a cytoskeletal protein which binds actin (Cao et al., 2001). Through interaction with cellular proteins, the cytoplasmic tail may be involved in intracellular signaling.

\subsection{Functions of ADAMs:}

Some somatic ADAMs play important roles in cell fate determination, cell migration, and axon and muscle development (Primakoff et al., 2000). For example, ADAM8 is a transmembrane glycoprotein expressed in immune cells, and contributes to neuron-glia interaction in the central nervous system (Schlomann et al., 2000). ADAM12-deficient mice have defects in the formation of adipose tissue and myogenesis (Kurisaki et al., 2003). Some ADAMs cleave EGFR ligands to activate the EGFR pathway which is responsible for cell migration, differentiation and tissue homeostasis (Liebmann, 2011, Wong, 2003). For example, ADAM17 is required for the shedding of EGFR ligands TGFa, HB-EGF, and amphiregulin, and ADAM10 is involved in cleaving two EGFR ligands EGF and betacellulin (Sahin et al., 2004). ADAM10 also processes both the $\mathrm{N}$ - and E-cadherins, which are involved in physiological functions such as neurulation, somitogenesis and tissue morphogenesis (Maretzky et al., 2005, Reiss et al., 2005). ADAM proteases also cleave cytokines and cytokine receptors, which play important roles in immune responses (Edwards et al., 2008, Jin et al., 2004, Kurzrock 2001). For example, ADAM17 cleaves TNF- $\alpha$ (tumor necrosis factor alpha), which is a proinflammatory cytokine and regulates immune cells (Black 2002). Finally, ADAMs are involved in a process called regulated intramembrane proteolysis (RIP). RIP is the cleaving of an integral membrane protein to release a soluble protein which is involved in cellular functions like apoptosis, cell proliferation, etc. (Edwards et al., 2008). Activation of the Notch receptor is a RIP process and ADAMs participate in this process. When the Notch receptor binds to the Notch ligand, it undergoes a series of proteolytic cleavages, which release the Notch intracellular domain. Ligand activates Notch and ADAM10 cleaves the extracellular S2 proteolytic site of Notch. This cleavage generates a 
membrane-bound "stub" of Notch which is cleaved further at S3 and S4 sites and releases the Notch intracellular domain that translocates to the nucleus and acts as a transcription regulator (Brou et al., 2000).

\subsection{Classification of tADAMs:}

More than half of the ADAM proteases are predominantly expressed in the male testis. Cho (2012) divided the mouse reproductive ADAMs into three groups: (I) intronless tADAMs, (II) tADAMs with multiple exons and introns, and (III) ADAM7 and ADAM28. In mice, ADAM7 and ADAM28 do not show expression in the testes, but are expressed in the epididymis (Kim et al., 2006). Phylogenetic analyses indicate that ADAM7 and ADAM28 do not cluster together with tADAMs (Figure 2). Group III, which consists of ADAM7 and ADAM28, was removed from the list of tADAMs based on these observations (Table 1, with Group III removed). But we keep the other two groups of tADAMs, i.e. Group I and Group II, based on their clustering in the phylogenetic tree (Figure 2).

Group I has 11 tAdam genes which lack introns in their coding sequences (Kim et al., 2006). ADAMs 4, 6, 24, 25, and 26 are exclusively expressed in germ cells of the mouse testis.

Group II tADAMs are predominantly expressed in germ cells of the testes. ADAMs in Group II lack active protease activity since they lack the consensus sequence of HExxHxxGxxH (Cho, 2012). There is evidence that some Group II tADAMs are also expressed in somatic tissues (Murase et al., 2008).

\subsection{Key roles of ADAMs in fertilization:}

TADAMs play key roles in fertilization, which is initiated by the adhesion of sperm and ovum. In mice, ADAM1, along with ADAM2 and ADAM3, are responsible for adhesion of the sperm to the 
zona pellucida, which is a glycoprotein membrane of the ovum (Evans, 2001). ADAM1, ADAM2 and ADAM3 are essential for sperm-egg fusion (Cerretti et al., 1999). ADAM1 and ADAM2 form a heterodimeric complex on the mature sperm (Primakoff et al., 1987; Blobel et al., 1992, Wolfsberg et al., 1995, Evans, 2002). ADAM2 and ADAM3 form a complex that helps the sperm to enter the oviduct in vivo, and promote sperm-egg interactions in vitro in mice (Cho, 2012). Trimeric complexes, such as ADAM2/ADAM3/ADAM4, ADAM2/ADAM3/ADAM5, and ADAM2/ADAM3/ADAM6, are formed on matured sperm, and are necessary for successful fertilization (Han et al., 2009). ADAM18 is proteolytically processed by cleaving both the proand metalloproteinase-like domains and retaining the disintegrin-like domain during epididymal transit to yield mature proteins on matured sperm (Frayne et al., 1998). ADAM21 is expressed in testicular somatic cells as well as germ cells (Yi et al., 2010). The Adam21 gene produces two types of transcripts. One is expressed in germ cells of the testis and has exon1 and exon2, while the other is expressed in testicular somatic cells and only has exon2 (Yi et al., 2010). It is unclear whether ADAM21 is involved in fertilization or spermatogenesis. ADAM24 is localized on the mature sperm acrosome after its prodomain has been removed. The cytoplasmic tail of ADAM24 acts as a substrate for protein kinase $C$ (PKC). After activation of ADAM24 by PKC, the sperm penetrates the zona pellucida (Zhu et al., 2001). In in vitro assays, Adam24-knockout mice displayed reduced fertility with polyspermic fertilization, which can lead to abnormal embryonic development (Zhu et al., 2009). ADAM25 and 26 (also called testase2 and testase3) are only found to be expressed in mouse spermatogenic process (Zhu et al., 1999, Brachvogel et al., 2003). Previous reports suggest that ADAM27 is expressed in the pachytene stage of spermatocytes of mice. Adam32 gene expression begins during meiotic prophase in spermatocytes (Choi et al., 2003). All of these studies on the reproductive ADAMs were performed on rodents. Since some of these genes are pseudogenes in the human genome, it is possible that functions of these tADAMs are species-specific. 


\subsection{Objectives:}

The objective was to understand the mechanism of evolution of tADAMs. We wanted to find whether there are tADAMs in non-placental mammals and in non-mammalian vertebrates.

ADAM9 is a sADAM which is widely expressed and highly conserved among all vertebrates that clusters along with the tADAMs in the phylogenetic analyses (Figure 2). We hypothesized that all the tADAMs originated from a common ancestor shared with ADAM9. With the help of phylogenetic analyses and syntenic analyses, we wanted to explore the evolutionary origin of tAdams.

\subsection{Significance of the study:}

The study on the evolution of reproductive ADAMs provided key insights into the functions of these proteins and the actual mechanisms of gene duplication. ADAMs are critical for fertilization and could be helpful in developing new methods of in vitro fertilization.

\section{MATERIALS AND METHODS}

\subsection{Identification of Adam genes in vertebrate}

\section{species tested (i.e. opossum, chick, lizard, and}

\section{frog):}

The sequences of annotated human and mouse ADAMs were used to identify Adam genes from other species using the BLAST program from NCBI. With human tADAM as queries, the NCBI, 
protein

BLAST

(ProteinBLAST[http://blast.ncbi.nlm.nih.gov/Blast.cgi?PROGRAM=blastp\&PAGE_TYPE=BlastS earch\&LINK_LOC=blasthome) was used to search against the species genome assembly. The representative species chosen were opossum, chick, lizard, and frog; other vertebrates such as rat, rabbit, pig, dog, Tasmanian devil, platypus, zebra finch, flycatcher, coelacanth, Japanese medaka, zebrafish, spotted gar and elephant shark were also included so that there was a representative organism from each vertebrate phylum. Three types of analyses i.e. phylogeny, synteny, and conservation of intron-exon boundaries were performed to identify the orthologs of predicted human and mouse ADAMs. The most appropriate BLAST hit i.e. the most significant match between sequences was selected. The lowest and closest to zero E-value is the most significant BLAST hit. The BLAST hit with E-value zero was selected, and the UCSC genome browser BLAT was used to search and identify the intron-exon boundaries in the tAdam genomic sequence (BLAT: https://genome.ucsc.edu/cgi-bin/hgBlat?command=start). Tissue expression patterns of specific Adam genes were obtained from the NCBI's UniGene website.

\subsection{Phylogenetic analyses:}

For phylogenetic analyses, amino acid sequences of ADAM from various species (Table 2) were aligned using default MUSCLE (MUltiple Sequence Comparison by Log Expectation) alignment parameters, and all positions containing gaps were eliminated (Edgar, 2004). Phylogenetic trees, including Bayesian, neighbor joining, and maximum likelihood trees, were constructed to investigate the evolutionary relationship among the ADAMs as described below.

Three types of tree building methods were used to see if the clustering of the clades are consistent when the phylogenetic trees are built using different tree building methods.

The Bayesian Markov Chain Monte Carlo analyses were conducted with MrBayes version 3.2.2 (Ronquist et al., 2003). This method is based on the posterior probability of the tree. The 
posterior probability is the probability that the tree is correct and the evolutionary model used in the analyses is assumed to be correct. The bases of Bayesian inference is the Bayes's theorem:

$$
\operatorname{Pr}[\text { Tree I Data }]=\frac{\operatorname{Pr}[\text { Data I Tree }] \times \operatorname{Pr}[\text { Tree }]}{\operatorname{Pr}[\text { Data }]}
$$

This equation is used to calculate the posterior probability distribution on trees ( $\operatorname{Pr}[\operatorname{Tree}$ I Data]) by combining prior probability of a phylogeny $(\operatorname{Pr}[\operatorname{Tree}])$ with the likelihood $(\operatorname{Pr}[\mathrm{Data} I \mathrm{Tree}])$. This suggests that the tree with higher posterior probability will be the favorable data for interpreting the phylogeny (Huelsenbeck et al., 2001). There are a number of numerical methods to estimate the posterior probability, the most commonly used is the Markov chain Monte Carlo (MCMC) method. There are two steps in the MCMC. First, a new tree is made randomly from the current tree, then either this tree is accepted or rejected based on a probability described by Metropolis et al. (1953) and Hastings (1970). This is repeated several times. MrModeltest 2.3 compares 24 models of nucleotide substitution. The best-fit model was selected as recommended by the Akaike Information Criterion (AIC) in MrModeltest version 2.3 in the Bayesian analysis (Nylander, 2004). A model selection is the comparison of all models using AIC (Akaike, 1974). Each analysis was run for 3,000,000 generations with six Markov chains to achieve a mean standard deviation less than 0.01. Posterior probabilities (PP) were calculated, and the model parameters were stabilized at 2,400,000 generations. Trees were sampled every 100 iterations. The final tree was visualized with FigTree v4.1.0 (FigTree: http://tree.bio.ed.ac.uk/software/figtree/) (Bahudhanapati et al., 2015).

Neighbor joining and maximum likelihood trees were generated by using the algorithms included in the MEGA 6.0 software. The neighbor joining tree is a data clustering algorithm based on similarity and distance matrix. The bootstrap consensus trees were inferred from 1000 replicates using the neighbor joining algorithm. The bootstrap value is the confidence 
value added to each internal node of the tree. This represents the number of times that the branch clustering occurs in the replicate trees when they are resampled. The evolutionary distances were computed using the Poisson correction method and are in the units of the number of amino acid substitutions per site (Tamura et al., 2003). The evolutionary history was also inferred by using the maximum likelihood method based on the JTT matrix-based model (Zuckerkandl et al., 1965). In this method, the tree that has the highest probability of generating the observed data is selected. JTT is an amino acid replacement model used in maximum likelihood to find the probabilities of change on tree branches. Several studies showed that JTT model is useful for the analysis of evolutionary history of membrane proteins. Since ADAMs are transmembrane proteins so we used the JTT model (Jones et al., 1994). The percentage of trees in which the associated taxa clustered together is shown next to the branches. Initial trees were obtained by applying the neighbor joining and BioNJ algorithms to a matrix of pairwise distances using the JTT model, and then selecting the topology with superior log likelihood value. JTT matrices used in this program MEGA6.0 were obtained from the source code of PHYLIP version 3.6 (Felsenstein et al., 1993-2001). All positions containing gaps and missing data were eliminated (Bahudhanapati et al., 2015).

\subsection{Syntenic analyses:}

For syntenic analyses, an individual Adam gene was entered into the search box of Genomicus (Louis et al., 2013), to find the position of tADAMs with respect to other genes for all the species mentioned above. Metazome (Jones et al., 1992) and the NCBI Map Viewer was also used to identify surrounding loci that are evolutionarily conserved. Data from these websites were analyzed to generate the syntenic diagrams (Bahudhanapati et al., 2015). 


\subsection{Identification of retroposition event among}

\section{the Adam genes:}

Using the UCSC Genome Browser BLAT search, potential retroposed Adam genes were identified as Adam genes with no or few $(\leq 2)$ introns. ADAM protein sequences were obtained from $\mathrm{NCBI}$, and the sequence was entered in the search bar of UCSC Genome Browser and the splice sites were determined (Bahudhanapati et al., 2015).

\section{RESULTS}

\subsection{TAdams in various animal species:}

Four Adam genes have been identified in the Ciona genome and twenty-two in zebrafish, but tAdam has not been identified in these non-mammalian species (Huxley-Jones et al., 2007). TAdams had only been identified in eutherians, so we started looking for tAdams in noneutherian vertebrates. We performed a search for tAdam genes in various vertebrate species, including frog (Xenopus tropicalis), lizard (Anolis carolinensis), chick (Gallus gallus), opossum (Monodelphis domestica), mouse (Mus musculus) and human (Homo sapiens) (Table 2), to understand the mechanism of evolution and the origin of tAdams. We found five tAdams in chick, nine in lizard and nine in opossum.

\subsection{Story of ADAM9 and ADAM9-like:}

ADAM9 is overexpressed in many human carcinomas, and plays an important role in tumorigenesis and angiogenesis. ADAM9 cleaves molecules such as EGF, EphB4, Flk-1, CD40, etc. The cleaving of these molecules plays important roles in tumorigenesis and angiogenesis (Peduto, 2009). Adam9 knockout mice show retinal degeneration gradually with 
age, but do not show any apparent developmental defects. Similarly, null mutations in ADAM9 result in cone-rod dystrophy in humans (Parry et al., 2009). We could not identify Adam9 in invertebrates like Drosophila and Ciona, but found the Adam9 gene in teleosts as well as spotted gar. The syntenic locations of the nearby genes of Adam9 in teleosts are rearranged relative to the position of Adam9 and its nearby genes in spotted gar, amphibians and higher vertebrates (Figure 3).

We identified an Adam9-like gene in fish, amphibian, reptilian and avian genomes (Figure 4). We could not identify this gene in any mammals; hence it may have been lost in mammals (Figure 4). The protein sequences of ADAM9-like from various species are more similar to ADAM9 than to other somatic ADAMs. This suggests that ADAMs 9 and 9-like share a common ancestor. Adam9 and Adam9-like are absent in the jawless lampreys, but have been identified in the cartilaginous fish elephant shark, one of the earliest vertebrate species. We were unable to identify which of these ADAMs evolved first because of the lack of genomic data available, but it can be speculated that both ADAM9 and ADAM9-like evolved early during vertebrate evolution.

\subsection{Group I and Group II tADAMs cluster with}

\section{ADAMs 9 and 9 -like forming a subfamily:}

Through an extensive search, we identified Group I and Group II tAdams in Anolis, chicken and opossum. Both Group I and Group II tADAMs of Anolis, chicken, opossum, mouse and human form clusters with high confidence with ADAMs 9 and 9-like in phylogenetic trees (Figure 2). In Xenopus tropicalis and fish genomes, we could not identify any definitive Group I or Group II tADAM, although ADAM16 of Xenopus laevis has been reported to be expressed predominantly in testis (Shilling et al., 1997) and clusters with ADAM9 and ADAM9-like in phylogenetic trees 
(Figure 2A). From the study, it can be said that Group I and Group II tADAMs and both the ADAM9 and ADAM9-like belong to the same ADAM subfamily. Since ADAM9 and ADAM9-like are found in all non-mammalian vertebrates including fishes and amphibians, both ADAM9 and 9-like probably emerged earlier than the tADAMs during vertebrate evolution, suggesting that Group I and Group II tADAMs evolved from ancient ADAM9 and/or 9-like.

In the previous study by Cho (2012), Adams 7 and 28 were classified under the tAdams as "reproductive" Adams. Cho classified the tAdams into three groups which we have mentioned earlier. The Group III consists of Adam 7 and 28, and was called reproductive Adams because Adam7 is predominantly expressed in the mouse epididymis (Cho, 2012). However, exploring the UniGene database, we found that human Adam28 is expressed in a wide variety of somatic tissues (data not shown). The phylogenetic analyses strongly indicate that ADAM 7 and 28 do not cluster with the tADAMs in the phylogenetic tree. This evidence suggests that they not belong to the subfamily that includes ADAMs 9, 9-like and tADAMs. Group III, which consists of ADAM 7 and 28 based on Cho's classification of "reproductive" ADAMs was removed and excluded from subsequent analyses.

\subsection{Evolution of Group II tAdam genes:}

We carried out a syntenic comparison of Group II tAdams for all representative amniote species and found that Group II tAdams cluster together in a genomic region next to Adam9 (Figure 4). We found two Group II tAdam genes in the lizard (Anolis carolinensis) and chicken (Gallus gallus) genomes. Three Group II tAdams were found in opossum, four in mouse, and five in the human genome. It is only in the mouse and rat genomes that the Adam2 gene is on a different chromosome (chromosomes 14 and 15, respectively), but all the other Group II tAdams are localized near Adam9 (Figure 3). No Adam gene was found near the locus of Adam9 in the $X$. tropicalis, coelacanth, or zebrafish genome (Figure 3). These results suggest that tandem 
duplication i.e. the event of copying the gene adjacent to the original copy; gave rise to Group II tAdam genes, and that an ancient Adam 9 was the founder gene of the very first Group II tAdam during evolution. Unequal crossing over during homologous recombination between paralogous sequences gives rise to tandemly duplicated genes. Deletion and inversion of genes are also the result of unequal crossing over in homologous recombination. The organization of Group II tAdam genes in an array on the same genomic locus is mainly a result of tandem duplication. Gene duplication also gives rise to pseudogenes. In the human genome, among the Group II tAdams we found that Adam3 and Adam5 are pseudogenes (HGNC: http://www.genenames.org/).

\subsection{Evolution of Group I tAdam genes: evidence for retroposition:}

A characteristic of Group I tAdams is that they contain none or very few introns. Retroposition is a mechanism in which a messenger RNA is reverse transcribed into cDNA with the help of reverse transcriptase, then the newly transcribed intronless DNA sequence from the mRNA gets inserted into the genome. Since the events in retroposition lead to intronless genes, it has been speculated that Group I tAdams are derived from retroposition. These Group I tAdams have lost the signature of retroposed genes i.e., the poly A tail because they evolved a long time ago. In our phylogenetic study, Group I tADAMs cluster with ADAM9 and 9-like and Group II tADAMs, so it can be speculated that Group I tADAMs share a common ancestor with Group II tADAM, ADAM9 and 9-like. Thus, the parental gene that gave rise to a specific Group I tAdam could be Adam9, 9-like, a Group II tAdam, or another Group I tAdam (Bahudhanapati et al., 2015). 


\subsection{A recent event of retroposition*:}

[*Note: This is Dr. Hari Bahudhanapti's work.]

We started looking for retroposed genes in the chicken, lizard, opossum, mouse and human that were derived from the ADAM9/9-like/tADAM subfamily in which the characteristic features of retroposition may still be well preserved.

In the opossum genome, we identified an additional copy of Adam 9 that has only one intron, which we named "Adam9b" (Figure 5). This gene is $\sim 99 \%$ identical to another copy, i.e. Adam9a, as per their nucleotide sequences. The Adam9a gene has 24 introns and conserved exon/intron boundaries with Adam9 in other vertebrate species (data not shown), hence is the opossum orthologue of Adam9. Since Adam $9 b$ has only one intron and a very high sequence homology to Adam9a, we believe that Adam $9 b$ was likely retroposed. We also found a polyA tail

in Adam9b (Figure 5) which supports the recent retroposition of Adam9b. In the event of retroposition, the cDNA copy is inserted randomly and the non-LTR retroposons like LINE has an adenosine-rich region at their 3 'ends. Since Adam9b has a polyA tail and is almost intronless, it indicates that it is a retroposed gene. We could not identify any other retroposed copy of other Adams in the opossum genome. This suggests that Adam9 may be a preferred target for retroposition.

\subsection{Tandem duplication of Group I tAdams:}

The Group I tAdams were found in clusters in some species. An example is Adam1 duplication. Genes near the Adam1 locus are conserved from frogs to humans, although Adam1 was not found in Xenopus tropicalis in this genomic region. This region in mammals and chicks is flanked by Tmem116, Erp29 on one side and Mapkapk5, Aldh2 on the other side. Anolis 
carolinensis has one Adam1, while the Chinese turtle has a duplicated Adam1 (Figure 6). Two copies of Adam1 are present in the chicken, opossum, mouse and human genome, suggesting tandem duplication. However, no orthology was found between mammalian and chicken Adam1a and $1 b$. So we hypothesize that either Adam1 has been duplicated separately in chicken and mammals, or before the divergence of mammals and one copy of it was lost in certain species such as Anolis carolinensis (Figure 6) (Bahudhanapati et al., 2015).

\section{Discussion:}

Gene duplication arises from unequal crossing over, retroposition, or chromosomal (or genome) duplication. These three different processes generate three different outcomes. Unequal crossing over results in tandem duplication, i.e. duplicated genes are present on the same chromosome close to each other. Position of crossing over determines whether the duplicated region has an entire gene or not. Retroposition can be characterized by loss of introns, loss of regulatory sequences, presence of polyA tails, or presence of flanking short direct repeats.

Pseudogenization or the loss of function of the duplicated gene is a common feature of gene duplication. We found 11 tAdam pseudogenes, which include both Group I and Group II tAdam genes (HGNC: http://www.genenames.org). These Group I tAdams which have probably originated from the event of retroposition, have a pre-mature stop codon. They are expressed and produce a truncated protein which is non-functional. So these Group I tAdams are not pseudogenes because of lack of transcription, which is commonly seen in retroposed genes since they do not carry the regulatory elements essential for transcription (Kaessmann et al., 2009). In retroposition, there is always a chance of insertion of the cDNA into a genomic location that is downstream of a promoter sequence; hence, causes the retroposed genes to get expressed (Vinckenbosch et al., 2006). Interestingly, retroposed genes and duplicated genes 
are commonly found to be expressed in the testes (Kaessmann et al., 2009, Vinckenbosch et al., 2006).

Gene duplication can work in two ways that can lead to evolution. One way is that the duplicated gene copy is producing proteins for a new function and the process is called neofunctionalization, or the multiple functions of the ancestral gene are divided into the newly duplicated genes and it is called subfunctionalization. The process of neofunctionalization will sustain if the new functions are advantageous. These duplicated tAdam genes which are predominantly expressed in testis, may also expand their expression to other tissues. It was found from the UniGene database, that Group II tAdams of mouse and human have transcripts expressed in some somatic tissues (Table 3).

\section{CONCLUSION}

In this study, we identified homologues of mouse and human tADAMs in the non-mammalian vertebrates chicken, lizard, and non-placental mammals such as the opossum. From our phylogenetic analyses, we found that the tADAMs cluster with ADAM9 as well as ADAM9-like, which we identified only in the non-mammalian vertebrates. It can be suggested that all the tADAMs have originated from an ancient somatic ADAM9. TADAMs were classified into three groups. We proposed to remove Group III, consisting of ADAM7 and ADAM28 from the classification because in our phylogenetic analyses Group III did not cluster with the tADAMs. We infer from our phylogenetic analyses that ADAMs 7 and 28 do not belong to the subfamily that includes ADAMs 9, 9-like and tADAMs.

The Group I tAdams are intronless, and are likely derived from retroposed transcripts, and some have undergone further tandem duplication in some vertebrates. One example of tandem duplication in Group I tAdams is the clustering of all the testase genes (nine Group I tAdams) in 
a single chromosomal region (Bahudhanapati et al., 2015). Phylogenetic analyses indicate that the Group I tAdams share a common ancestor with the Group II tAdams, Adam9 and 9-like. Thus, the parental gene that gave rise to a specific Group I tAdam could be Adam9, 9-like, a Group II tAdam, or another Group I tAdam. Group II tAdams cluster together in a genomic region next to Adam9 suggesting that tandem duplication from an ancient Adam 9 gave rise to all the Group II tAdams.

We found an intronless Adam $9 \mathrm{~b}$ containing a polyA tail in opossum, which represents one of the most recent retroposition events. Retroposed elements are found in high percentage in the opossum genome (Mikkelsen et al., 2007). But we could not identify any other retroposed copy of other Adams in the opossum genome. The tAdam loci are prone to duplication and retroposition and hence provide excellent examples for studying gene duplication and evolution. In the future, it would be interesting to study the expression and function of the non-eutherian tAdam genes identified in this study. 


\section{FIGURES:}

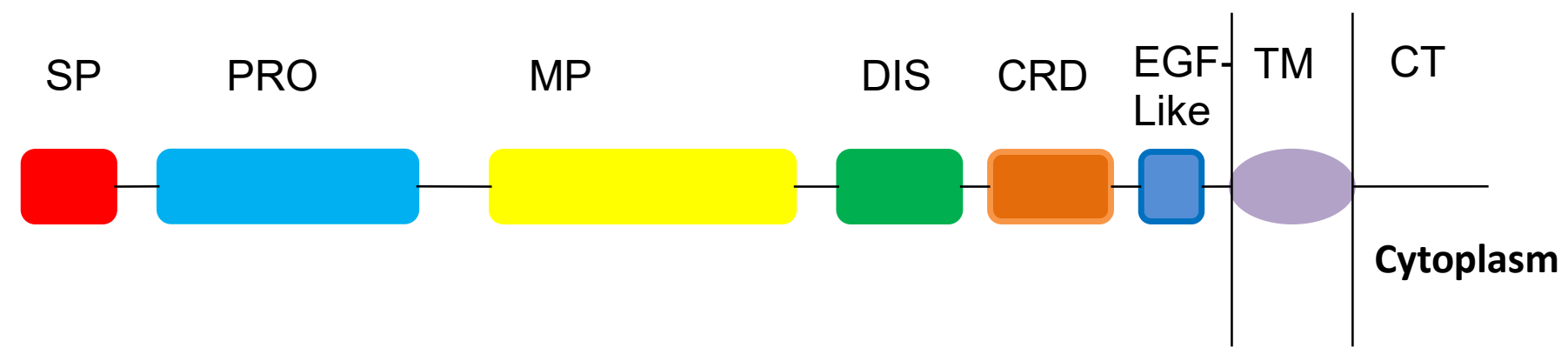

Figure 1: Structure of ADAM. The domain structure comprises of SP (signal peptide), PRO (prodomain), MP (metalloproteinase domain), DIS (disintegrin domain), CRD (cysteine-rich domain), EGF (epidermal growth factor-like domain), TM (transmembrane region), and CT (cytoplasmic tail). 


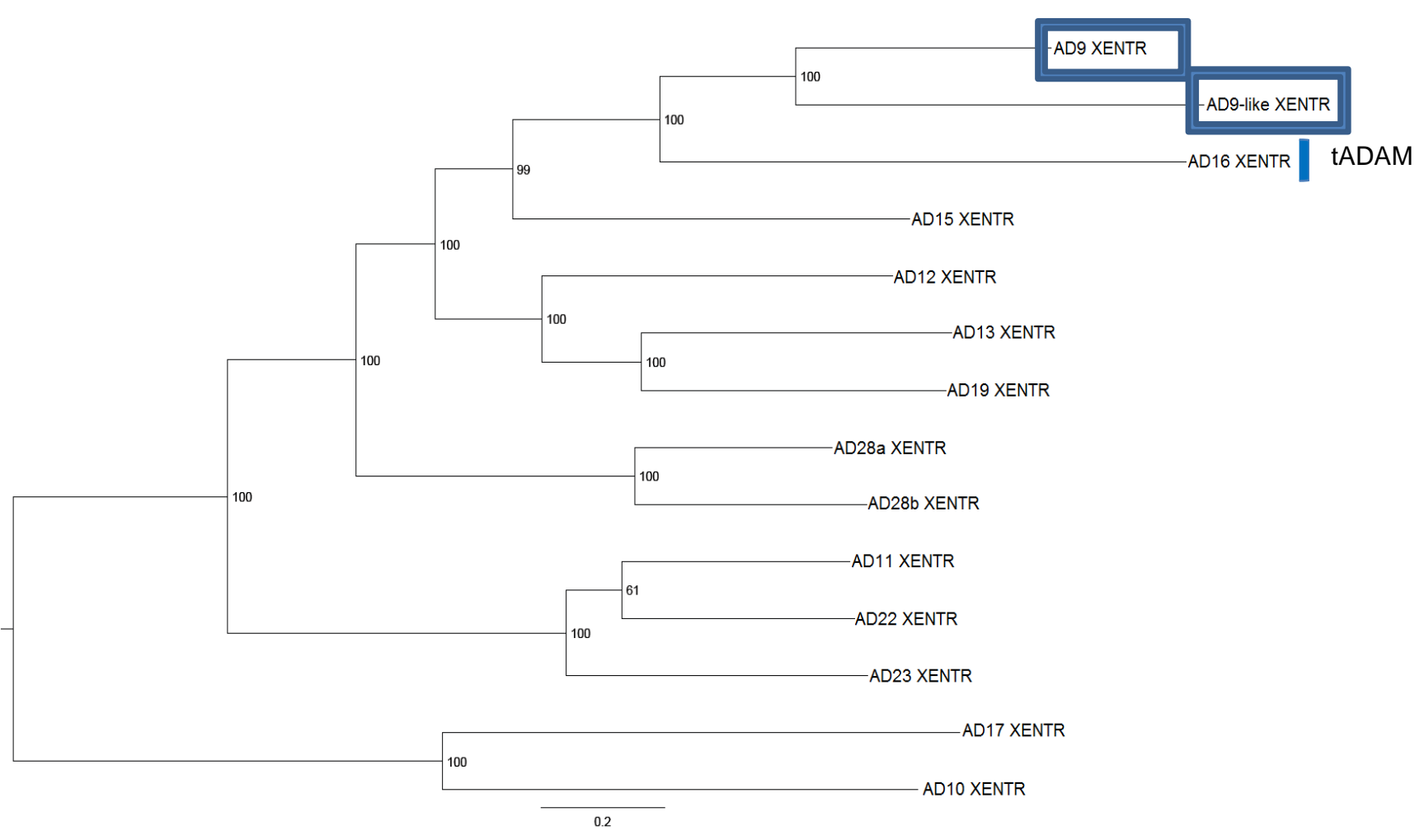

Figure 2A: Bayesian tree of ADAMs for frog (Xenopus tropicalis).

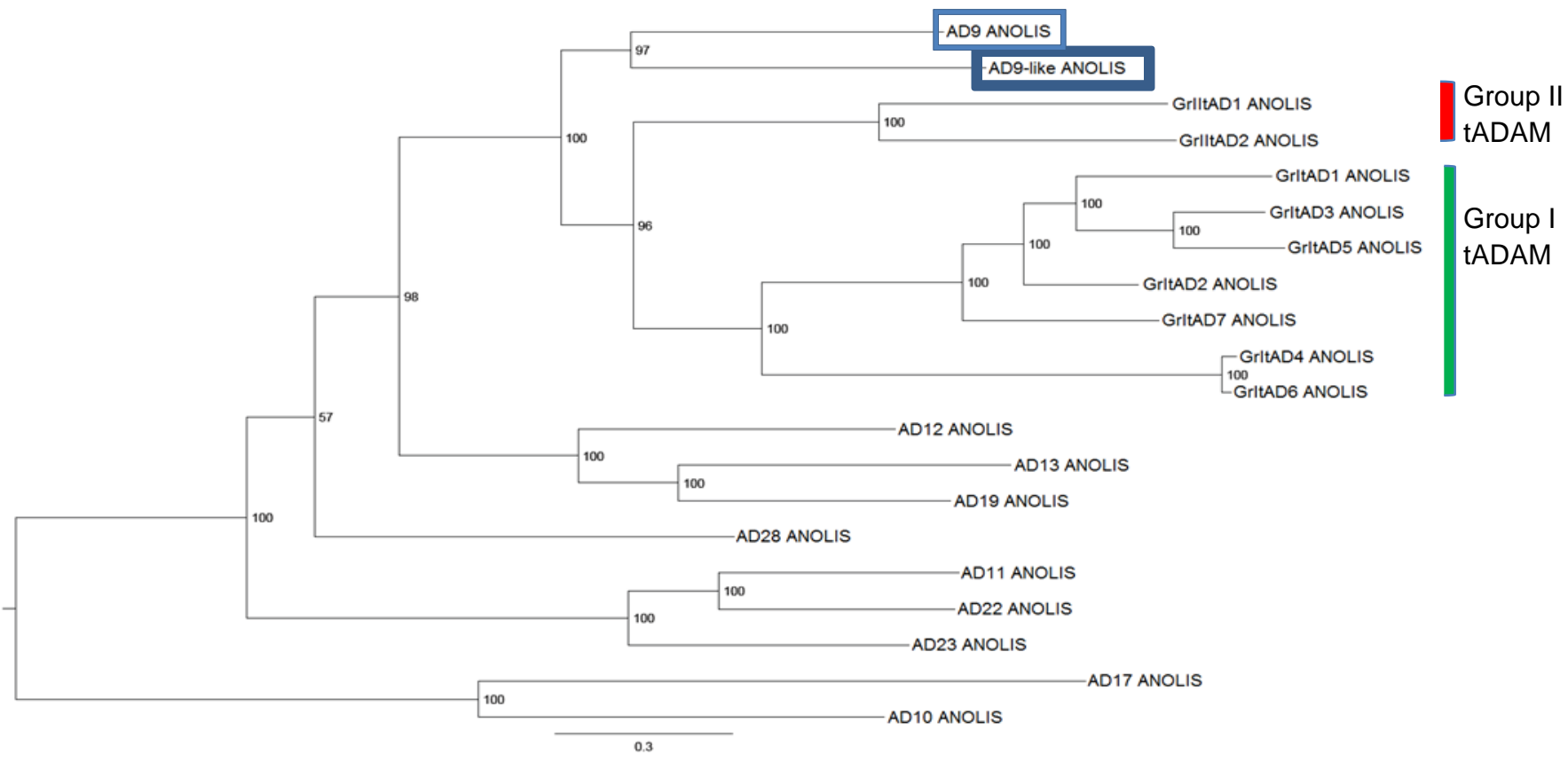

Figure 2B: Bayesian tree of ADAMs for lizard (Anolis carolinensis). 


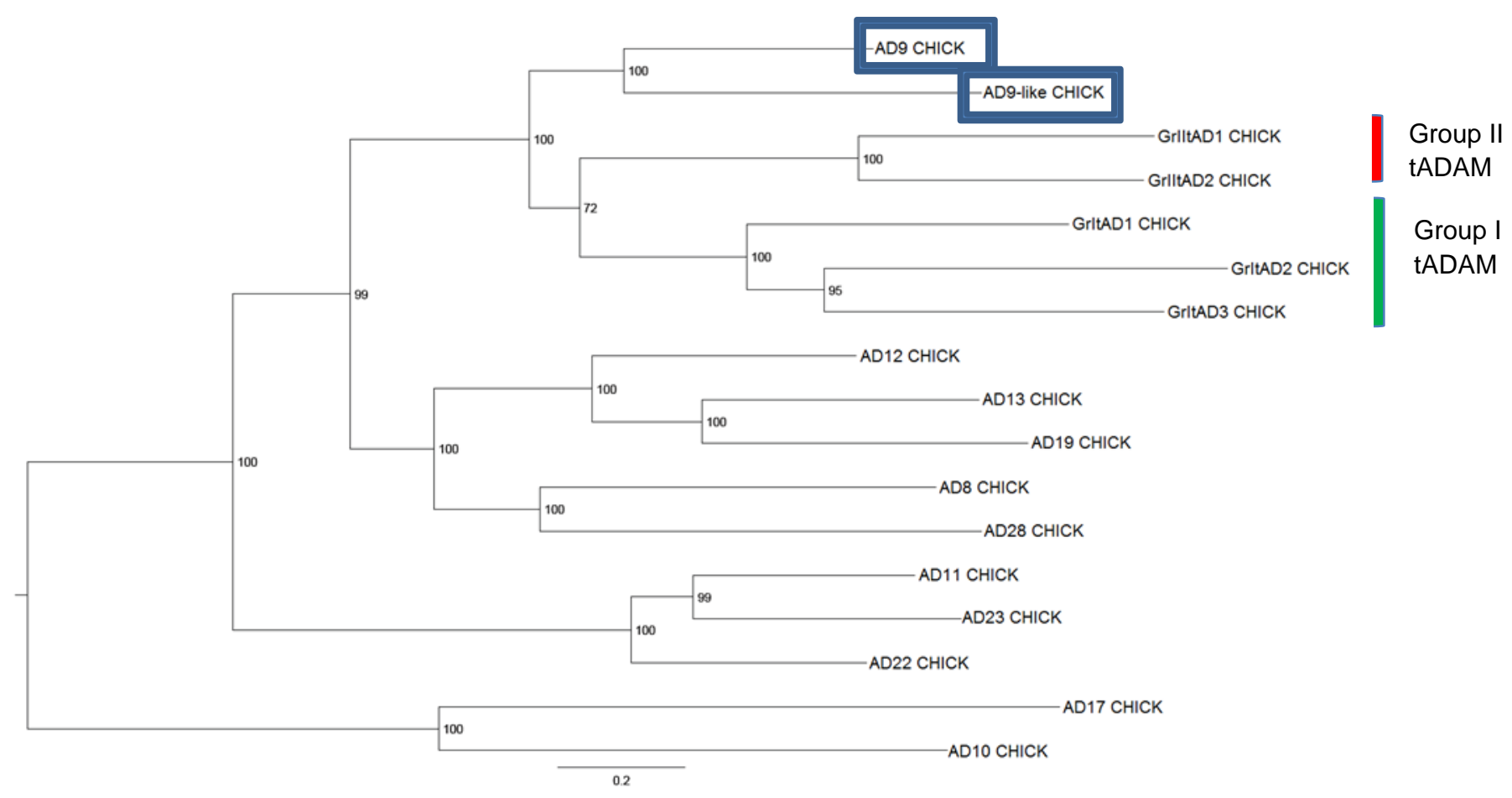

Figure 2C: Bayesian tree of ADAMs for chicken (Gallus gallus)

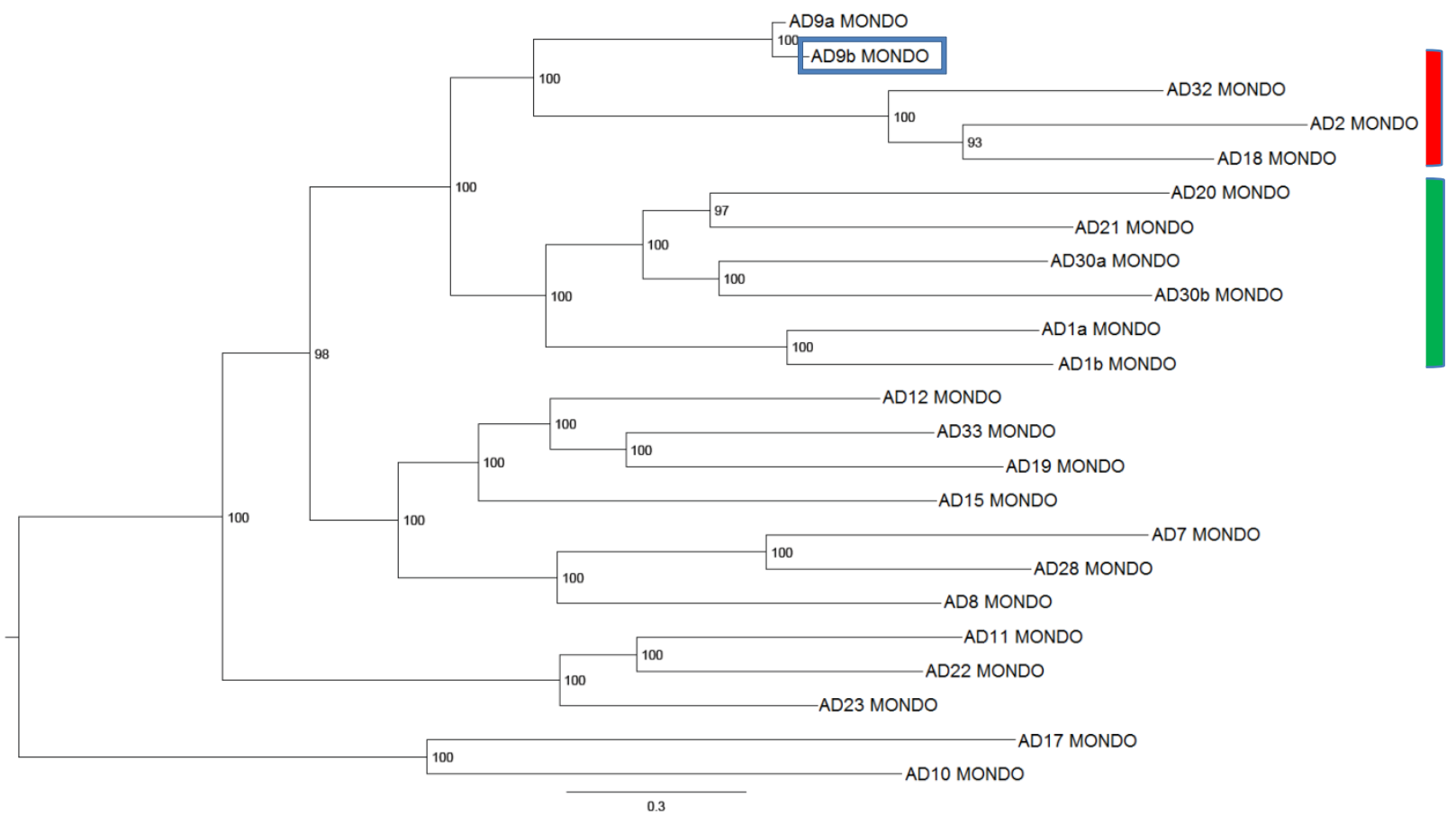

Group II tADAM

Group I tADAM

Figure 2D: Bayesian tree of ADAMs for opossum (Monodelphis domestica). 


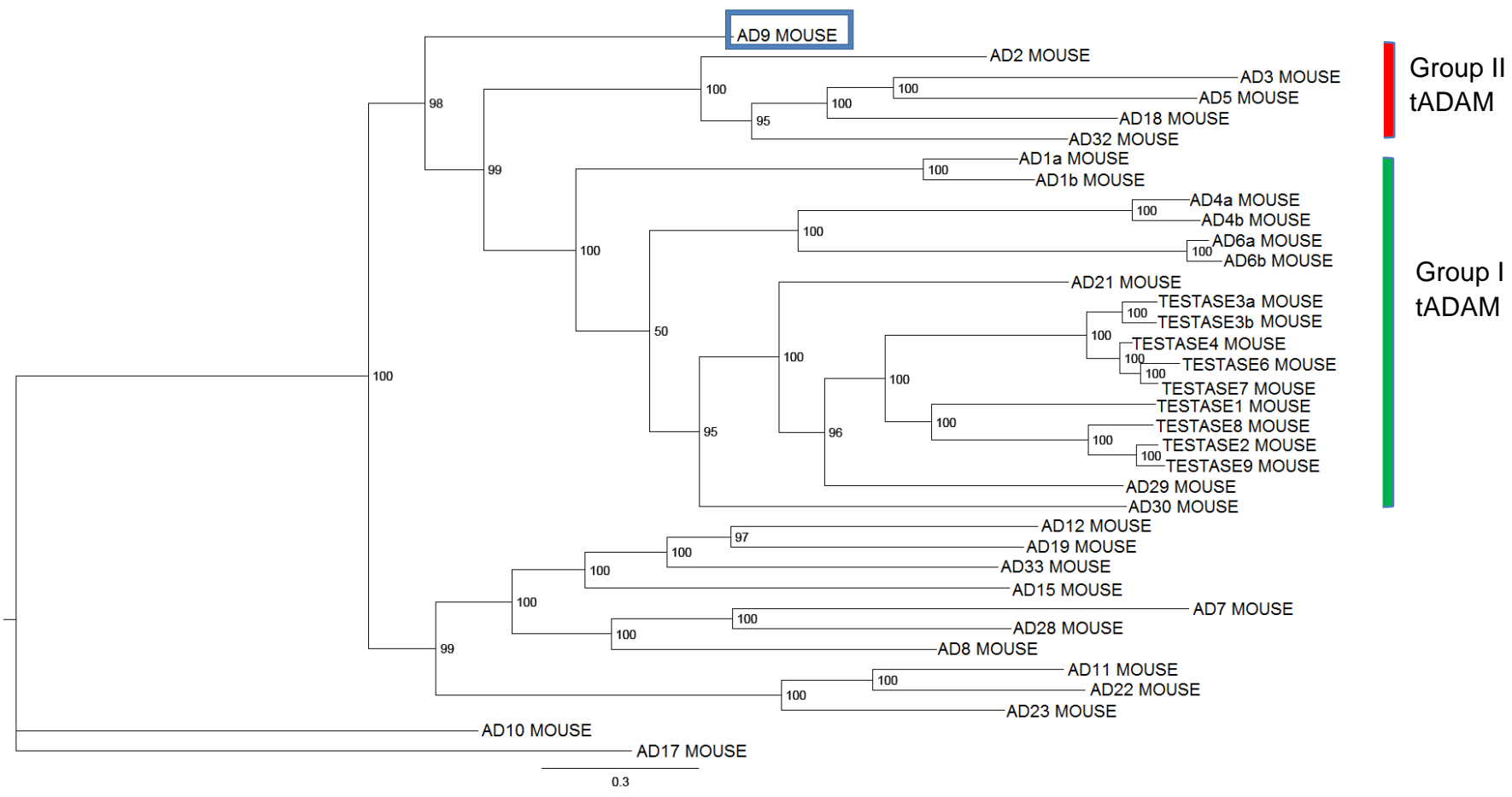

Figure 2E: Bayesian tree of ADAMs for mouse (Mus musculus).

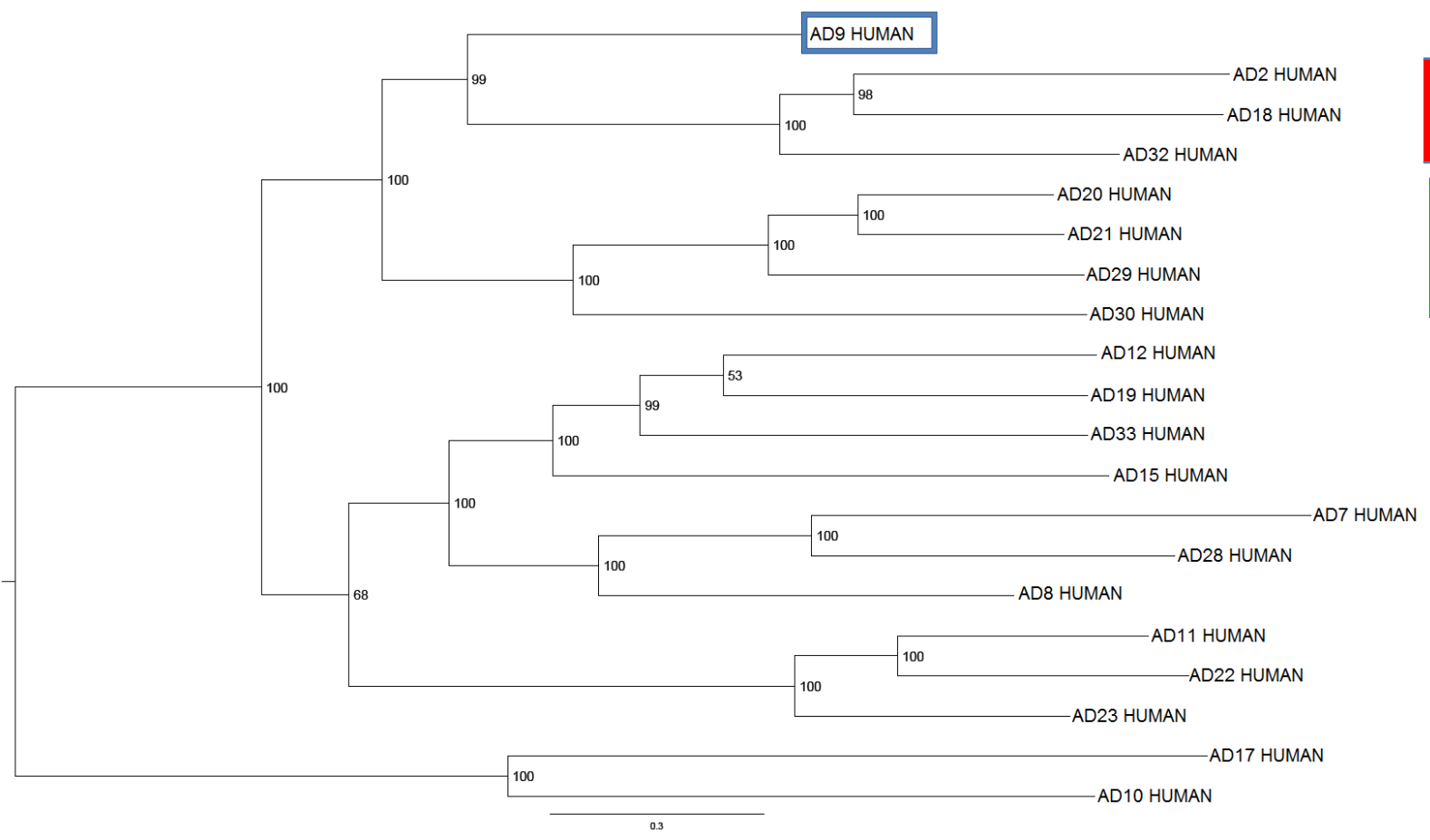

Figure 2F: Bayesian tree of ADAMs for human (Homo sapiens). 


\begin{tabular}{|c|c|c|c|c|c|c|c|c|c|}
\hline $\begin{array}{l}\mathrm{Tm} 2 \\
\mathrm{~d} 2\end{array}$ & Adam9 & Adam32 & Adam5 & Adam3 & Adam18 & Adam2 & Ido1 & Ido2 & $\begin{array}{l}\text { Human: } \\
\text { Chr8 }\end{array}$ \\
\hline $\begin{array}{l}\text { Tm2 } \\
\mathrm{d} 2\end{array}$ & Adam9 & Adam 32 & Adam5 & Adam3 & Adam18 & & Ido1 & Ido2 & $\begin{array}{l}\text { Mouse: } \\
\text { Chr8 }\end{array}$ \\
\hline $\begin{array}{l}1 \mathrm{~m} 2 \\
\mathrm{~d} 2\end{array}$ & Adam9 & Adam18 & Adam 32 & & & Adam2 & Ido1 & Ido2 & $\begin{array}{l}\text { Opossum: } \\
\text { Chr1 }\end{array}$ \\
\hline & Adam 9 & & & & & & & Ido2 & $\begin{array}{l}\text { Chick: } \\
\text { Chr22 }\end{array}$ \\
\hline & Adam9 & & & & & & & Ido2 & $\begin{array}{l}\text { Anolis: } \\
\text { GL343418 } \\
.1\end{array}$ \\
\hline $\begin{array}{l}m 2 \\
d 2\end{array}$ & Adam9 & Ggh.2 & & & & & & & $\begin{array}{l}X . \\
\text { tropicalis: } \\
\text { JH172670.1 }\end{array}$ \\
\hline & Adam9 & & & & & & & Ido2 & $\begin{array}{l}\text { Coelacant } \\
\mathrm{h}: \\
\mathrm{JH1} 126671.1\end{array}$ \\
\hline $\begin{array}{c}\text { Nudt } \\
18\end{array}$ & Adam9 & Ogdha & & Ppiaa & SIc18a1 & & & & $\begin{array}{l}\text { Zebrafish: } \\
\text { Chr8 }\end{array}$ \\
\hline & Adam9 & & Zmiz2 & Ppiaa & SIc18a1 & & & & $\begin{array}{l}\text { Medaka: } \\
\text { Chr9 }\end{array}$ \\
\hline & am & & & & & & & & $\begin{array}{l}\text { Spotted gar: } \\
\text { LG1 }\end{array}$ \\
\hline
\end{tabular}

Figure 3: Syntenic analyses of the Group II tAdams. Most of the Group II tAdams lie next to Adam9 in all vertebrates, except for Adam2 in rodents. 


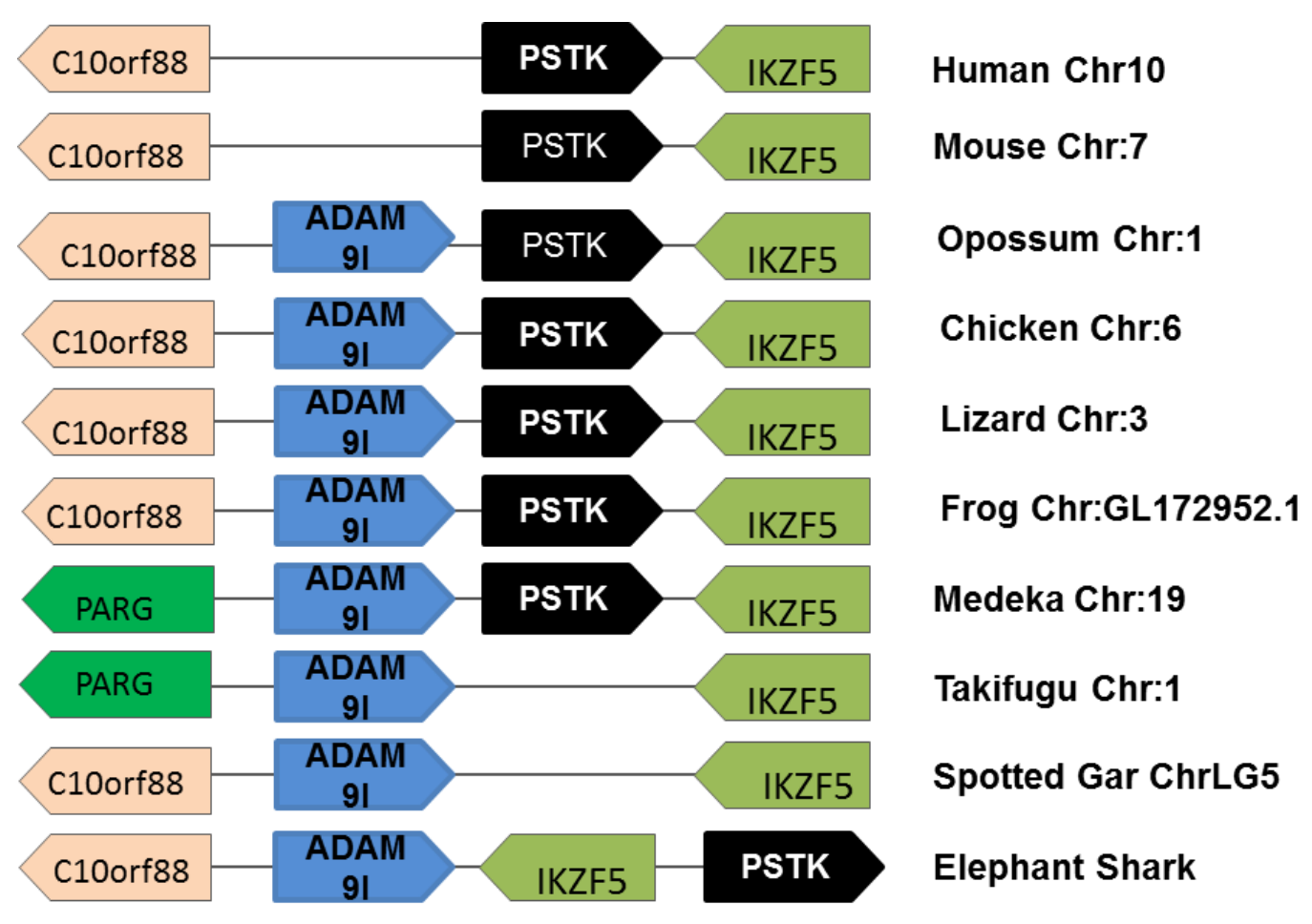

Figure 4: Syntenic analysis of Adam9-like gene. Syntenic analysis of Adam9-like copy from lower non-mammalian vertebrates to cartilaginous elephant shark showed that it is highly conserved, while it disappeared in the course of evolution in higher mammals. 
A.

\begin{tabular}{|c|c|c|c|c|c|c|c|c|}
\hline $\operatorname{Tm} 2 \mathrm{~d} 2$ & Ad9a & Ad32 & Ad5 & Ad3 & Ad18 & Ad2 & Id01 & Ido2 \\
\hline
\end{tabular}

B.

\begin{tabular}{|c|c|c|c|c|c|c|}
\hline ADAM & $\begin{array}{l}\text { Gl number } \\
\text { Opossum }\end{array}$ & Location & $\begin{array}{l}\text { Presence of } \\
\text { Introns }\end{array}$ & $\begin{array}{l}\text { Query } \\
\text { Covered }\end{array}$ & $\begin{array}{l}\text { Human } \\
\text { ADAM }\end{array}$ & $\begin{array}{c}\text { sequence } \\
\text { identity } \\
\text { to human }\end{array}$ \\
\hline ADAM9a & 126304095 & $\begin{array}{c}\text { Chr1: } \\
574025879- \\
574137608\end{array}$ & 24 Exons & 94 & ADAM 9 & $99 \%$ \\
\hline ADAM9b & 334347013 & $\begin{array}{c}\text { Chr7: } \\
\text { 65540811- } \\
65543391\end{array}$ & Intronless & 92 & ADAM 9 & \\
\hline
\end{tabular}

C.

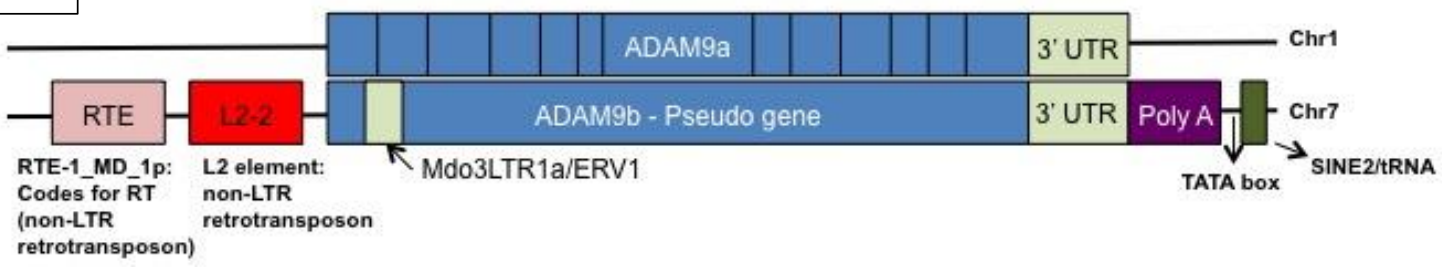

Figure 5: Comparison between Adam9a and Adam9b of opossum. (A) Location of Adam 9a and $9 \mathrm{~b}$ in the opossum genome. (B) Comparison table of Adam9a and Adam9b of opossum. (C) The gene structure of Adam9b. The Adam9b pseudogene contains a polyA sequence, and the only intron was identified as an opossum retroposon (Mdo3LTR1a/ERV1), which was likely inserted after the original retroposition event that generated Adam9b. The structure of the ADAM9a mRNA is shown. The black vertical lines in ADAM9a mRNA represent splice sites (Courtesy of Dr. Hari Bahudhanapati). 


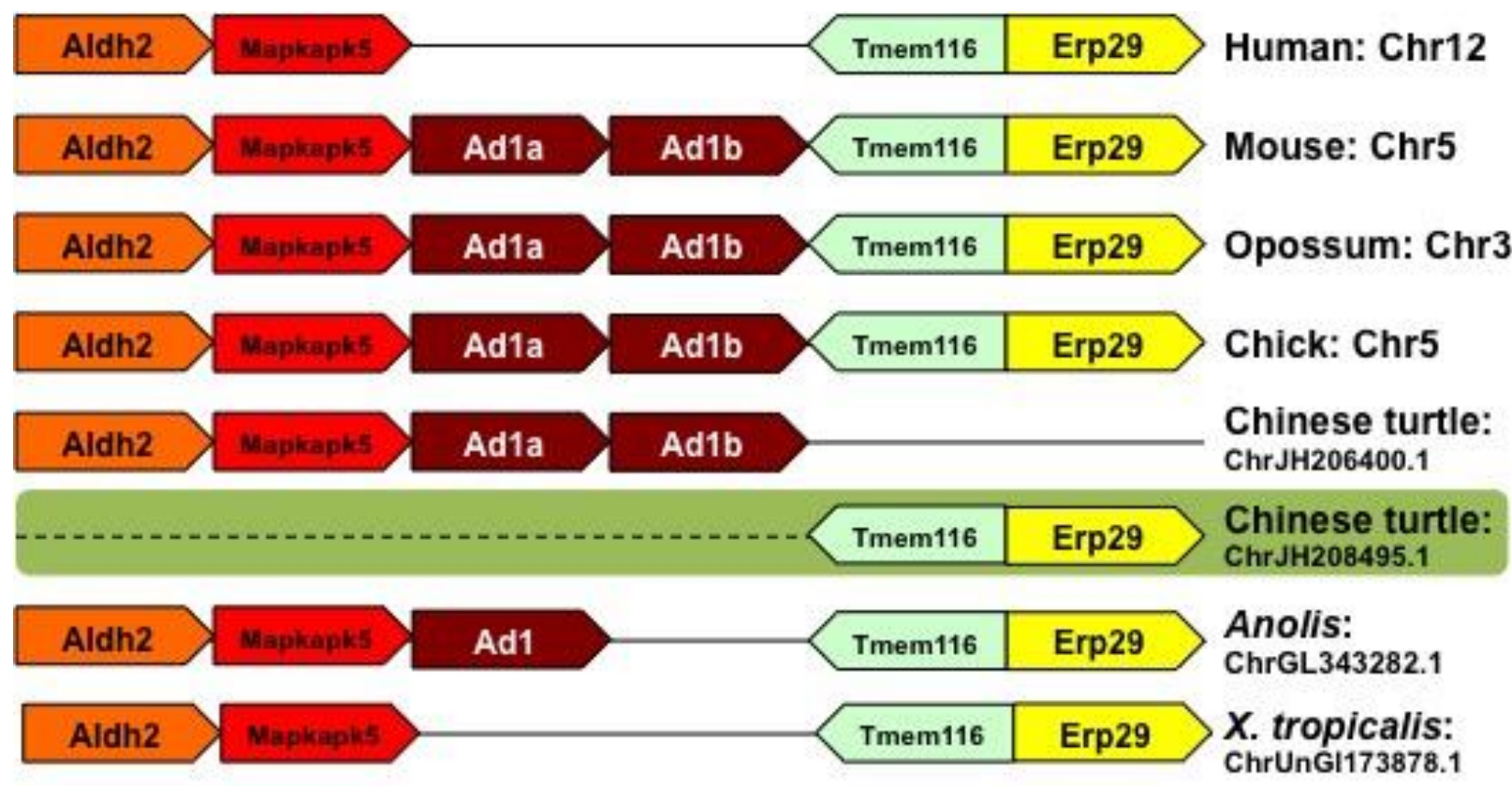

Figure 6: Adam1 duplication. Expansion of Adam1 through tandem duplication in chicken, opossum and mouse genome. Adam1 gene is not found in the $X$. tropicalis genome and only one copy was found in the Anolis genome. 
Table 1: Classification of mouse tADAMs.

\begin{tabular}{|l|l|}
\hline Group & ADAMs \\
\hline I & $1,4,6,20,21,24,25,26,29$, \\
& 30, and 34 \\
\hline II & $2,3,5,18$ and 32 \\
\hline
\end{tabular}

Note: This table is modified from Cho, 2012 by removing Group III consisting of ADAM7 and ADAM28. 
Table 2. Accession numbers of ADAM proteins used in phylogenetic analyses.

\begin{tabular}{|c|c|c|}
\hline Species & Protein Name & Accession Number \\
\hline Human & ADAM2 & Q99965 \\
\hline Human & ADAM7 & Q9H2U9 \\
\hline Human & ADAM8 & P78325 \\
\hline Human & ADAM9 & Q13443 \\
\hline Human & ADAM10 & 014672 \\
\hline Human & ADAM11 & O75078 \\
\hline Human & ADAM12 & O43184 \\
\hline Human & ADAM15 & Q13444 \\
\hline Human & ADAM17 & P78536 \\
\hline Human & ADAM18 & Q9Y3Q7 \\
\hline Human & ADAM19 & Q9H013 \\
\hline Human & ADAM20 & O43506 \\
\hline Human & ADAM21 & Q9UKJ8 \\
\hline Human & ADAM22 & Q9P0K1 \\
\hline Human & ADAM23 & 075077 \\
\hline Human & ADAM28 & Q9UKQ2 \\
\hline Human & ADAM29 & Q9UKF5 \\
\hline Human & ADAM30 & Q9UKF2 \\
\hline Human & ADAM32 & Q8TC27 \\
\hline Human & ADAM33 & Q9BZ11 \\
\hline Mouse & ADAM1a & Q60813 \\
\hline Mouse & ADAM1b & Q8R534 \\
\hline Mouse & ADAM2 & Q60718 \\
\hline Mouse & ADAM3 & NP_033749 \\
\hline Mouse & ADAM4a & AAN77877 \\
\hline Mouse & ADAM4b & NP_001034084 \\
\hline Mouse & ADAM5 & Q3TTE0 \\
\hline Mouse & ADAM6a & NP_777479 \\
\hline Mouse & ADAM6b & NP_001009545 \\
\hline Mouse & ADAM7 & O35227 \\
\hline Mouse & ADAM8 & Q05910.3 \\
\hline Mouse & ADAM9 & NP_001257925 \\
\hline Mouse & ADAM10 & O35598.2 \\
\hline Mouse & ADAM11 & Q9R1V4.2 \\
\hline Mouse & ADAM12 & Q61824.2 \\
\hline
\end{tabular}




\begin{tabular}{|c|c|c|}
\hline Mouse & ADAM15 & NP_001257925 \\
\hline Mouse & ADAM17 & Q9Z0F8.3 \\
\hline Mouse & ADAM18 & Q9R157 \\
\hline Mouse & ADAM19 & O35674.2 \\
\hline Mouse & ADAM21 & Q9JI76 \\
\hline Mouse & ADAM22 & Q9R1V6.2 \\
\hline Mouse & ADAM23 & Q9R1V7.1 \\
\hline Mouse & ADAM28 & Q9JLN6.3 \\
\hline Mouse & ADAM29 & Q811Q4 \\
\hline Mouse & ADAM30 & AAO38664 \\
\hline Mouse & ADAM32 & Q8K410 \\
\hline Mouse & ADAM33 & Q923W9.3 \\
\hline Mouse & TESTASE1/ADAM24 & Q9R160 \\
\hline Mouse & TESTASE2/ADAM25 & Q9R159 \\
\hline Mouse & TESTASE3a/ADAM26a & EQR158.2 \\
\hline Mouse & TESTASE3b/ADAM26b & NP_001009547 \\
\hline Mouse & TESTASE4/ADAM34 & NP_665688 \\
\hline Mouse & TESTASE6/ADAM36 & CAD65874 \\
\hline Mouse & TESTASE7/ADAM37 & CAD65875 \\
\hline Mouse & TESTASE8 /ADAM38 & AAI50794 \\
\hline Mouse & TESTASE9/ADAM39 & NP_001020551 \\
\hline Opossum & ADAM1a & XP_001371130.2 \\
\hline Opossum & ADAM1b & XP_001379089.1 \\
\hline Opossum & ADAM2 & XP_007476447.1 \\
\hline Opossum & ADAM4 & XP_001376240.1 \\
\hline Opossum & ADAM7 & XP_001372800.2 \\
\hline Opossum & ADAM8 & XP_007486259.1 \\
\hline Opossum & ADAM9a & XP_001381888.1 \\
\hline Opossum & ADAM9b & XP_001371117.2 \\
\hline Opossum & ADAM10 & XP_001377651.2 \\
\hline Opossum & ADAM11 & XP_001375121.2 \\
\hline Opossum & ADAM12 & XP_001367874.2 \\
\hline Opossum & ADAM15 & XP_007482077 \\
\hline Opossum & ADAM17 & XP_007476214.1 \\
\hline Opossum & ADAM18 & XP_007476434 \\
\hline Opossum & ADAM19 & XP_007474485 \\
\hline Opossum & ADAM20 & $X P \_001376230$ \\
\hline Opossum & ADAM22 & XP_007505027 \\
\hline Opossum & ADAM23 & XP_001370554 \\
\hline Opossum & ADAM28 & XP_007477887 \\
\hline Opossum & ADAM30a & XP_007485363 \\
\hline Opossum & ADAM30b & XP_007485362 \\
\hline
\end{tabular}




\begin{tabular}{|c|c|c|}
\hline Opossum & ADAM30c & XP_001367215 \\
\hline Opossum & ADAM30d & XP_001376215.1 \\
\hline Opossum & ADAM32 & XP_007476443 \\
\hline Opossum & ADAM33 & XP_007496940 \\
\hline Chicken & ADAM8 & $X P \_421552.4$ \\
\hline Chicken & ADAM9 & NP_001026567.2 \\
\hline Chicken & ADAM9L & $X P \_421805.4$ \\
\hline Chicken & ADAM10 & NP_989592.2 \\
\hline Chicken & ADAM11 & $X P \_425842.4$ \\
\hline Chicken & ADAM12 & NP_001136322.1 \\
\hline Chicken & ADAM13 & NP_001075887.1 \\
\hline Chicken & ADAM17 & NP_001026567.2 \\
\hline Chicken & ADAM19 & NP_001182051.1 \\
\hline Chicken & ADAM22 & NP_001138700.1 \\
\hline Chicken & ADAM23 & NP_001138702.1 \\
\hline Chicken & ADAM28 & XP_004947615.1 \\
\hline Chicken & Grll tADAM1 & XP_004947684.1 \\
\hline Chicken & Grll tADAM2 & $X P \_003642600.2$ \\
\hline Chicken & Grl tADAM1 & NP_001264719.1 \\
\hline Chicken & Grl tADAM2 & NP_996860.1 \\
\hline Chicken & Grl tADAM3 & XP_003642244.2 \\
\hline Anolis & Grl tADAM1 & XP_003228944.1 \\
\hline Anolis & Grl tADAM2 & XP_008116367.1 \\
\hline Anolis & Grl tADAM3 & XP_003225712.1 \\
\hline Anolis & Grl tADAM4 & XP_008115539.1 \\
\hline Anolis & Grl tADAM5 & XP_008116366.1 \\
\hline Anolis & Grl tADAM6 & XP_008107167.1 \\
\hline Anolis & Grl tADAM7 & XP_008116368.1 \\
\hline Anolis & Grll tADAM1 & ENSACAG00000009283* \\
\hline Anolis & Grll tADAM2 & ENSACAG00000029425* \\
\hline Anolis & ADAM9 & XP_003226892.1 \\
\hline Anolis & ADAM9-L & XP_008104933.1 \\
\hline Anolis & ADAM10 & XP_003228118.1 \\
\hline Anolis & ADAM11 & XP_003222558.1 \\
\hline Anolis & ADAM12 & XP_003218654.1 \\
\hline Anolis & ADAM13 & XP_008120251.1 \\
\hline Anolis & ADAM17 & XP_008115827.1 \\
\hline Anolis & ADAM19 & XP_003223525.1 \\
\hline Anolis & ADAM22 & XP_008110692.1 \\
\hline Anolis & ADAM23 & XP_003223597.1 \\
\hline Anolis & ADAM28 & XP_003226913.1 \\
\hline
\end{tabular}




\begin{tabular}{|c|c|c|}
\hline Xenopus & ADAM9 & NP_001233130.1 \\
\hline Xenopus & ADAM9-L & XP_004915886.1 \\
\hline Xenopus & ADAM10 & NP_001037869.1 \\
\hline Xenopus & ADAM11 & NP_001243157.1 \\
\hline Xenopus & ADAM12 & ABD52382.1 \\
\hline Xenopus & ADAM13 & NP_001035102.1 \\
\hline Xenopus & ADAM15 & ADK56765.1 \\
\hline Xenopus & ADAM16 & AAI70249.1 \\
\hline Xenopus & ADAM17 & NP_001182159.1 \\
\hline Xenopus & ADAM19 & NP_001035105.1 \\
\hline Xenopus & ADAM22 & O42596.2 \\
\hline Xenopus & ADAM23 & NP_001233135.1 \\
\hline Xenopus & ADAM28a & NP_001120446.1 \\
\hline Xenopus & ADAM28b & NP_001233133.1 \\
\hline Platypus & ADAM9 & XP_001519072.2 \\
\hline Zebrafish & ADAM9 & NP_001004678.1 \\
\hline Zebrafish & ADAM9-L & NP_001107911.1 \\
\hline Medaka & ADAM9 & XP_004072878.1 \\
\hline Medaka & ADAM9-L & XP_004080608.1 \\
\hline Shark & ADAM9 & XP_007902115.1 \\
\hline Shark & ADAM9-L & XP_007883217.1 \\
\hline & \multicolumn{2}{|c|}{${ }^{*}$ Ensemble accession number } \\
\hline
\end{tabular}


Table 3: Expression of Adam9 and Group II tAdams transcripts in mouse and human.

\begin{tabular}{|c|c|c|c|c|c|}
\hline \multirow[b]{2}{*}{ Gene } & \multirow[b]{2}{*}{ Tissue } & \multicolumn{2}{|c|}{ Mouse } & \multicolumn{2}{|c|}{ Human } \\
\hline & & $\begin{array}{l}\text { Transcript } \\
\text { per million }\end{array}$ & $\begin{array}{l}\text { Gene EST/Total } \\
\text { EST in pool }\end{array}$ & $\begin{array}{l}\text { Transcript } \\
\text { per million }\end{array}$ & $\begin{array}{l}\text { Gene EST/Total } \\
\text { EST in pool }\end{array}$ \\
\hline \multirow{18}{*}{ Adam9 } & adipose tissue & 649 & $1 / 1540$ & 77 & $1 / 12866$ \\
\hline & adrenal gland & -- & -- & 60 & $2 / 32940$ \\
\hline & ascites & -- & -- & 75 & $3 / 39834$ \\
\hline & bladder & 429 & $7 / 16283$ & 133 & $4 / 29860$ \\
\hline & bone & 440 & $15 / 34066$ & -- & -- \\
\hline & bone marrow & 29 & 4/136333 & -- & -- \\
\hline & brain & 33 & $16 / 475384$ & 21 & 24/1092688 \\
\hline & connective tissue & 504 & $10 / 19807$ & 120 & $18 / 149072$ \\
\hline & embryonic tissue & 112 & $76 / 677554$ & 56 & $12 / 212896$ \\
\hline & epididymis & 322 & $1 / 3101$ & -- & -- \\
\hline & eye & 80 & $15 / 185387$ & 23 & $5 / 208840$ \\
\hline & heart & 36 & $2 / 54558$ & 44 & $4 / 89524$ \\
\hline & mammary gland & 141 & $43 / 303048$ & -- & -- \\
\hline & nerve & -- & -- & 128 & $2 / 15535$ \\
\hline & testis & 32 & $4 / 121820$ & 27 & $12 / 435204$ \\
\hline & uterus & 291 & $2 / 6855$ & 21 & $5 / 232093$ \\
\hline & sympathetic ganglion & 400 & 4/9989 & -- & -- \\
\hline & vascular & -- & -- & 271 & $14 / 51649$ \\
\hline \multirow{6}{*}{ Adam2 } & brain & -- & -- & 1 & $2 / 1092688$ \\
\hline & connective tissue & -- & -- & 20 & $3 / 149072$ \\
\hline & lungs & 10 & 1/99799 & -- & -- \\
\hline & prostate & -- & -- & 10 & 2/189536 \\
\hline & testis & 147 & $36 / 435204$ & 82 & $36 / 435204$ \\
\hline & thymus & 2 & $1 / 121153$ & -- & -- \\
\hline \multirow{3}{*}{ Adam3 } & brain & -- & -- & 3 & $4 / 1092688$ \\
\hline & spleen & 86 & $8 / 92417$ & -- & -- \\
\hline & testis & 1264 & $154 / 121820$ & 117 & $51 / 435204$ \\
\hline \multirow{3}{*}{ Adam5 } & connective tissue & 50 & $1 / 19807$ & 46 & $7 / 149072$ \\
\hline & eye & 5 & $1 / 185387$ & -- & -- \\
\hline & testis & 582 & $71 / 121820$ & 68 & $30 / 435204$ \\
\hline \multirow{4}{*}{ Adam18 } & bladder & -- & -- & 33 & $1 / 29860$ \\
\hline & connective tissue & -- & -- & 46 & 7/149072 \\
\hline & embryonic tissue & -- & -- & 9 & $2 / 212896$ \\
\hline & testis & 82 & $10 / 121820$ & 64 & $28 / 435204$ \\
\hline \multirow{6}{*}{ Adam 32} & adipose tissue & -- & -- & 77 & $1 / 12866$ \\
\hline & brain & -- & -- & 3 & $4 / 1092688$ \\
\hline & connective tissue & -- & -- & 114 & $17 / 149072$ \\
\hline & embryonic tissue & 7 & $5 / 677554$ & -- & -- \\
\hline & kidney & -- & -- & 4 & $1 / 210778$ \\
\hline & testis & 213 & $26 / 121820$ & 124 & $54 / 435204$ \\
\hline
\end{tabular}




\section{REFERENCES}

1. Bahudhanapati H, Bhattacharya S, and Wei S; Evolution of vertebrate Adam genes; duplication of testicular Adams from ancient Adam9/9-like loci. PlosOne, 2015, 10(8)

2. BLAT: https://genome.ucsc.edu/cgi-bin/hgBlat?command=start.

3. Brou C, Logeat F, Gupta N, Bessia C, LeBail O, Doedens JR, Cumano A, Roux P, Black RA, Israël A. "A novel proteolytic cleavage involved in Notch signaling: the role of the disintegrin-metalloprotease TACE". Mol Cell. 2000, 5

4. Black RA. "Tumor necrosis factor-alpha converting enzyme". Int J Biochem Cell Biol. 2002, $34(1): 1-5$.

5. Brachvogel B, Reichenberg D, Beyer S, Jehn B, von der Mark K, Bielke W. "Molecular cloning and expression analysis of a novel member of the Disintegrin and Metalloprotease-Domain (ADAM) family". Gene 2003, 288, 203-210.

6. Brocker CN, Vasiliou V, Nebert DW. "Evolutionary divergence and functions of the ADAM and ADAMTS gene families". Human Genomics. 2009, 1. 43 -55

7. Bond JS, Beynon RJ. "The astacin family of metalloendopeptidases." Protein Sci. 1995, 1247-61.

8. Borroto A, Ruiz-Paz S, de la Torre TV, Borrell-Pages M, Merlos-Suarez A, Pandiella A, Blobel CP, Baselga J, Arribas J. "Impaired trafficking and activation of tumor necrosis factor-alpha-converting enzyme in cell mutants defective in protein ectodomain shedding". J Biol Chem. 2003, 278(28)

9. Bode W, Grams F, Reinemer P, Gomis-Rüth FX, Baumann U, McKay DB, Stöcker W. "The Metzincin-Superfamily of Zinc-Peptidases". Adv in Expt Med and Biol. 1996, 389. 
10. Blobel CP, Wolfsberg TG, Turck CW, Myles DG, Primakoff $P$, White JM. "A potential fusion peptide and an integrin ligand domain in a protein active in sperm-egg fusion". Nat. 1992, 356: 248-252.

11. Cousin H, Abbruzzese G, Kerdavid E, Gaultier A, Alfandari D. "Translocation of the cytoplasmic domain of ADAM13 to the nucleus is essential for Calpain8-a expression and cranial neural crest cell migration." Dev Cell. 2011, 20(2): 256-263.

12. Cong L, Jia J. "Promoter polymorphismsbond which regulate ADAM9 transcription are protective against sporadic Alzheimer's disease". Neurobiol Aging. 2009, 32 (1)

13. Cho C. "Testicular and epididymal ADAMs: expression and function during fertilization". Nat Rev Urol. 2012, 9: 550-560.

14. Cao Y, Kang Q, Zolkiewska A. "Metalloprotease-disintegrin ADAM 12 interacts with alpha-actinin-1".Biochem J. 2001, 353-61.

15. Cerretti DP, DuBose RF, Black RA, Nelson N. "Isolation of two novel metalloproteinasedisintegrin (ADAM) cDNAs that show testis-specific gene expression." Biochem Biophys Res Commun.1999, 263(3):810-5.

16. Choi I, Woo JM, Hong S, Jung YK, Kim DH, Cho C. "Identification and characterization of ADAM32 with testis-predominant gene expression". Gene. 2003,304:151-162.

17. Choi H, Lee B, Jin S, Kwon JT, Kim J, Jeong J. "Identification and characterization of promoter and regulatory regions for mouse Adam2 gene expression". Mol Biol Rep. 2013, 40:787-796.

18. Edwards DR, Handsley MM, Pennington CJ. "The ADAM metalloproteinases". Mol Aspects Med. 2008, 29(5): 258-289.

19. Eto K, Huet C, Tarui T, Kupriyanov S, Liu HZ, Puzon-McLaughlin $\quad$ W, Zhang XP, Sheppard D, Engvall E, Takada Y. "Functional classification of ADAMs based on a 
conserved motif for binding to integrin alpha 9beta 1: implications for sperm-egg binding and other cell interactions". J Biol Chem. 2002, 277(20):17804-10.

20. Evans, J. P. "The molecular basis of sperm-oocyte membrane interactions during mammalian fertilization". Hum. Reprod. 2002, 8, 297-311.

21. Evans J.P. " Fertilin $\beta$ and other ADAMs as integrin ligands: Insights into cell adhesion and fertilization". BioEssays, 2001, 23: 628-639.

22. Edgar RC. "MUSCLE: multiple sequence alignment with high accuracy and high throughput". Nucleic Acids Res. 2004, 32: 1792-1797.

23. Frayne J, Jury JA, Barker HL, Hall L. "The MDC family of proteins and their processing during epididymal transit”. J Reprod Fertil Suppl. 1998, 53:149-55.

24. FigTree: http://tree.bio.ed.ac.uk/software/figtree/

25. Gaultier A., Cousin H., Darribere T., Alfandari D. "ADAM13 disintegrin and cysteine-rich domains bind to the second heparin-binding domain of fibronectin". J. Biol. Chem. 2002, 277 (26), 23336-44

26. Huxley-Jones J, Clarke TK, Beck C, Toubaris G, Robertson DL, Boot-Handford RP. "The evolution of the vertebrate metzincins; insights from Ciona intestinalis and Danio rerio". BMC Evol Biol. 2007, 7: 63.

27. Hooper NM. "Families of zinc metalloproteases". FEBS. 1994, 354 (1)

28. Han C, Choi E, Park I, Lee B, Jin S, Kim do H, Nishimura H, Cho C. "Comprehensive analysis of reproductive ADAMs: relationship of ADAM4 and ADAM6 with an ADAM complex required for fertilization in mice". Biol Reprod. 2009, 80(5):1001-8

29. Huelsenbeck John., Rannala B, and Masly PJ., "An Introduction to Bayesian Inference of Phylogeny". http://www.sciencemag.org/site/feature/data/1050262.pdf

30. Jin P, Panelli MC, Marincola FM, Wang E. "Cytokine polymorphism and its possible impact on cancer". Immunol Res. 2004, 30:181 - 90. 
31. Jones DT, Taylor WR, Thornton JM. "The rapid generation of mutation data matrices from protein sequences". Comput Appl Biosci. 1992, 8: 275-282.

32. Jones D.T, Taylor W.R, Thornton J.M. "A mutation data matrix for transmembrane proteins". FEBS Lett.1994, 339:269-275.

33. Kaessmann $\mathrm{H}$, Vinckenbosch $\mathrm{N}$, Long M. "RNA-based gene duplication: mechanistic and evolutionary insights". Nat Rev Genet. 2009, 10: 19-31.

34. Kim T, Oh J, Woo JM, Choi E, Im SH, Yoo YJ, Kim DH, Nishimura H, Cho C. "Expression and relationship of male reproductive ADAMs in mouse". Biol Reprod. 2006, 74(4):744-50

35. Kenny PA, Bissell MJ. Targeting TACE-dependent EGFR ligand shedding in breast cancer. J Clin Invest. 2007, 117 (2):337-45

36. Kurisaki T, Masuda A, Sudo K, Sakagami J, Higashiyama S, Matsuda Y, Nagabukuro A, Tsuji A, Nabeshima Y, Asano M, Iwakura Y, Sehara-Fujisawa A. "Phenotypic analysis of Meltrin alpha (ADAM12) -deficient mice: involvement of Meltrin alpha in adipogenesis and myogenesis". Mol Cell Biol. 2003, 23(1)

37. Kurzrock R. "Cytokine deregulation in cancer". Biomed Pharmacother. 2001, 55:543 744. Black RA. "Tumor necrosis factor-alpha converting enzyme". Int J Biochem Cell Biol. 2001, 34 (1): 1-5.

38. Louis A, Muffato M, Roest Crollius H. "Genomicus: five genome browsers for comparative genomics in eukaryote". Nucleic Acids Res. 2013, 700-5

39. Liebmann C. "EGF receptor activation by GPCRs: an universal pathway reveals different versions." Mol Cell Endocrinol. 2011, 15;331(2):222-31

40. Maretzky T, Reiss K, Ludwig A, Buchholz J, Scholz F, Proksch E, de Strooper B, Hartmann D, Saftig P. "ADAM10 mediates E-cadherin shedding and regulates 
epithelial cell-cell adhesion, migration, and beta-catenin translocation." Proc Natl Acad Sci. U S A, 2005, 102

41. Murase S, Cho C, White JM, Horwitz AF. "ADAM2 promotes migration of neuroblasts in the rostral migratory stream to the olfactory bulb". Eur J Neurosci. 2008, 27(7).

42. Mikkelsen TS, Wakefield MJ, Aken B, Amemiya CT, Chang JL, et al. "Genome of the marsupial Monodelphis domestica reveals innovation in non-coding sequences". Nat. 2007, 447: 167-177.

43. Nakahama K, Yoshimura K, Marumoto R, Kikuchi M, Lee IS, Hase T, Matsubara H. Cloning and sequencing of Serratia protease gene. Nucleic Acids Res. 1986, 14(14):5843-55

44. Primakoff $P$, Hyatt $H$, Tredick-Kline J. "Identification and purification of a sperm surface protein with a potential role in sperm-egg membrane fusion". J Cell Biol. 1987, 104: 141149

45. Primakoff $P$, Myles DG. "The ADAM gene family: surface proteins with adhesion and protease activity". Trends Genet. 2000, 16(2):83-7.

46. ProteinBLAST[http://blast.ncbi.nlm.nih.gov/Blast.cgi?PROGRAM=blastp\&PAGE_TYPE= BlastSearch\&LINK_LOC=blasthome]

47. Peduto L. "ADAM9 as a potential target molecule in cancer". Curr Pharm Des. 2009, 15 (20): 2282-7.

48. Parry DA, Toomes C, Bida L, Danciger M, Towns KV, McKibbin M, Jacobson SG, Logan CV, Ali M, Bond J, Chance R, Swendeman S, Daniele LL, Springell K,Adams M, Johnson CA, Booth AP, Jafri H, Rashid Y, Banin E, Strom TM, Farber DB, Sharon D, Blobel CP, Pugh EN Jr, Pierce EA, Inglehearn CF. " Loss of the metalloprotease ADAM9 leads to cone-rod dystrophy in humans and retinal degeneration in mice". Am J Hum Genet. 2009, 84: 683-691. 
49. Rooke J, Pan D, Xu T, Rubin GM. "KUZ, a conserved metalloprotease-disintegrin protein with two roles in Drosophila neurogenesis". Sci. 1996, 273(5279).

50. Roghani M, Becherer JD, Moss ML, Atherton RE, Erdjument-Bromage $H$, Arribas J, Blackburn RK, Weskamp G, Tempst P, Blobel CP. Metalloprotease-Disintegrin MDC9: Intracellular Maturation and Catalytic Activity. J. Biol. Chem. 1999, 274:3531-3540.

51. Reiss K, Maretzky T, Ludwig A, Tousseyn T, de Strooper B, Hartmann D, Saftig P. "ADAM10 cleavage of $\mathrm{N}$-cadherin and regulation of cell-cell adhesion and beta-catenin nuclear signalling". EMBO J. 2005, 24,

52. Ronquist F, Huelsenbeck JP. "MrBayes 3: Bayesian phylogenetic inference under mixed models". Bioinformatics 2003, 19: 1572-1574.

53. Repeatmasker: http://www.repeatmasker.org.

54. Shilling FM, Kratzschmar J, Cai H, Weskamp G, Gayko U, Leibow J, Myles DG, Nuccitelli R, Blobel CP. "Identification of metalloprotease/disintegrins in Xenopus laevis testis with a potential role in fertilization”. Dev Biol. 1997, 186: 155-164.

55. Sahin U, Weskamp G, Kelly K, Zhou HM, Higashiyama S, Peschon J, Hartmann D, Saftig P, Blobel CP. "Distinct roles for ADAM10 and ADAM17 in ectodomain shedding of six EGFR ligands." J Cell Biol. 2004, 164.

56. Schlomann U, Rathke-Hartlieb S, Yamamoto S, Jockusch H, Bartsch JW. "Tumor necrosis factor alpha induces a metalloprotease-disintegrin, ADAM8 (CD 156): implications for neuron-glia interactions during neurodegeneration”. J Neurosci. 2000, 20(21):7964-71.

57. Schlondorff J., Blobel C.P. "Metalloprotease-disintegrins: Modular proteins capable of promoting cell-cell interactions and triggering signals by protein-ectodomain shedding". J. Cell. Sci. 1999, 112:3603-3617. 
58. Schiffmacher AT, Padmanabhan R, Jhingory S, Taneyhill LA. "Cadherin-6B is proteolytically processed during epithelial-to-mesenchymal transitions of the cranial neural crest”. Mol Biol Cell. 2014, 25(1)

59. Seals DF, Courtneidge SA. "The ADAMs family of metalloproteases: multidomain proteins with multiple functions". Genes \& Dev. 2003, 17: 7-30

60. Stocker, W., Grams, F., Baumann U., Reinemer P., Gomis-Ruth F. X.,McKay, D. B. and Bode, W. "The metzincins - topological and sequential relations between the astacins, adamalysins, serralysins, and matrixins (collagenases) define a superfamily of zinc-peptidases". Protein Sci. 1995, 823-840.

61. Tamura K, Stecher G, Peterson D, Filipski A, Kumar S. "MEGA6: Molecular Evolutionary Genetics Analysis version 6.0." Mol Biol Evol. 2003, 30: 2725-2729.

62. Vinckenbosch N, Dupanloup I, Kaessmann H. "Evolutionary fate of retroposed gene copies in the human genome”. Proc Natl Acad Sci U S A. 2006, 103: 3220-3225.

63. Wolfsberg TG, Bazan JF, Blobel CP, Myles DG, Primakoff P, White JM. "The precursor region of a protein active in sperm-egg fusion contains a metalloprotease and a disintegrin domain: structural, functional, and evolutionary implications". Proc Natl Acad Sci U S A. 1993, 90: 10783-10787.

64. Wolfsberg TG, Straight PD, Gerena RL, Huovila AP, Primakoff P, Myles DG, White JM. "ADAM, a widely distributed and developmentally regulated gene family encoding membrane proteins with a disintegrin and metalloprotease domain”. Dev Biol. 1995, 169: 378-383.

65. White JM. "ADAMs: modulators of cell-cell and cell-matrix interactions". Curr Opin Cell Biol. 2003, 15(5):598-606. 
66. Wong RW. "Transgenic and knockout mice for deciphering the roles of EGFR ligands". Cell Mol Life Sci. 2003, 60(1):113-8.

67. Wei S, Whittaker CA, Xu G, Bridges LC, Shah A, White JM, Desimone DW. "Conservation and divergence of ADAM family proteins in the Xenopus genome". BMC Evol Biol. 2010, 10:211

68. Yi C, Woo JM, Han C, Oh JS, Park I, Lee B, Jin S, Choi H, Kwon JT, Cho BN, Kim do H, Cho C. "Expression analysis of the Adam21 gene in mouse testis". Gene Expr Patterns. 2010, 10(2-3):152-8.

69. Zhu G.Z., Lin Y., Myles D.G., Primakoff P. "Identification of four novel ADAMs with potential roles in spermatogenesis and fertilization”. Gene 1999, 234, 227-237.

70. Zhu GZ, Gupta S, Myles DG, Primakoff P."Testase1 (ADAM 24) a Sperm Surface Metalloprotease Is Required for Normal Fertility in Mice”. Mol Reprod Dev. 2009, $76: 1106-1114$

71. Zhu GZ, Myles DG, Primakoff P. “Testase 1 (ADAM 24) a plasma membrane-anchored sperm protease implicated in sperm function during epididymal maturation or fertilization". J Cell Sci. 2001;114

72. Zuckerkandl E, Pauling L., "Evolutionary divergence and convergence in proteins". Edited in Evolving Genes and Proteins by Bryson V, Vogel HJ, Academic Press. 1965, 97-166. 


\section{Appendix}

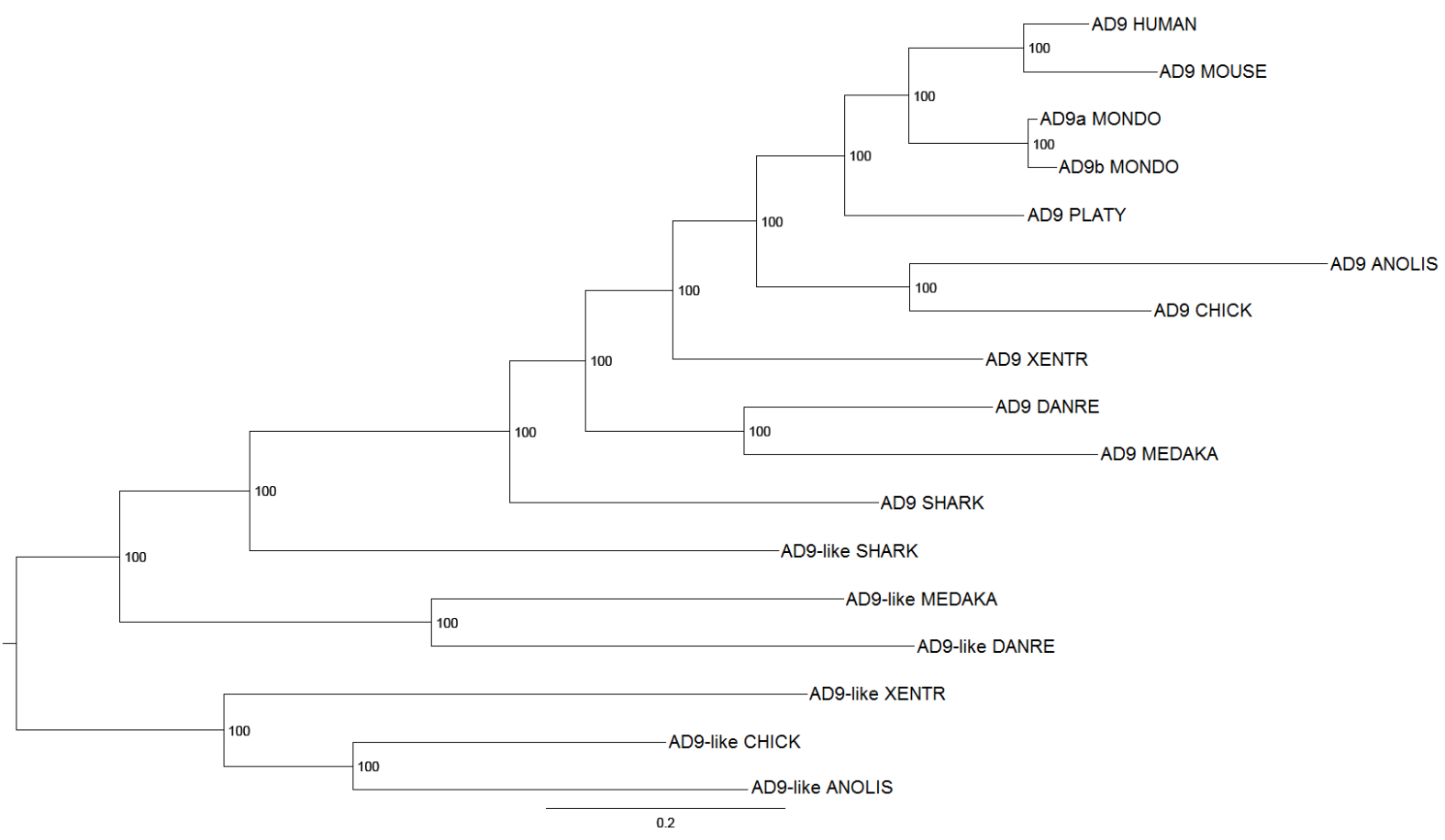

Figure 1: Bayesian tree of ADAM9 for all tested vertebrates. 


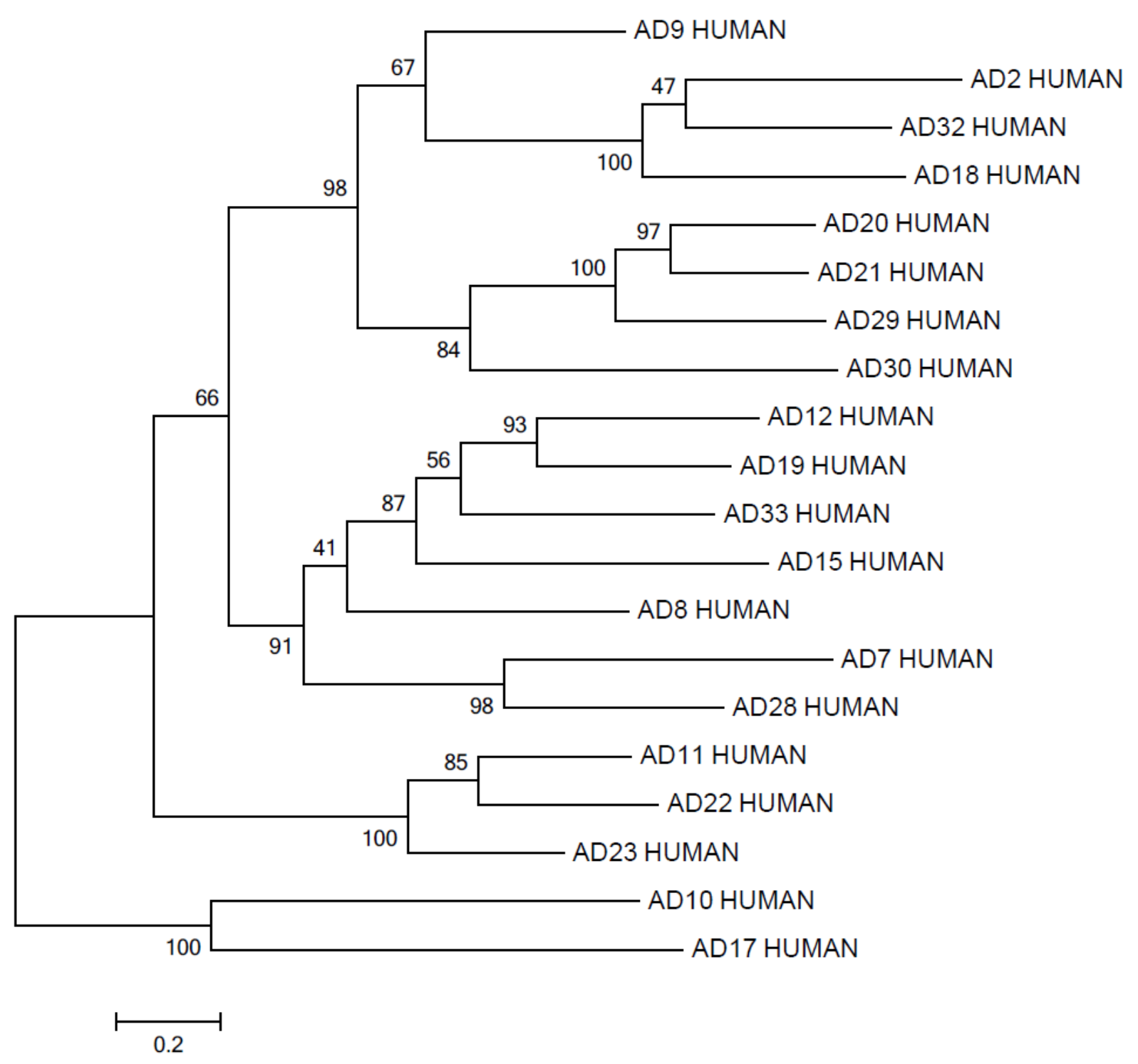

Figure 2: Maximum likelihood tree for human ADAMs. 


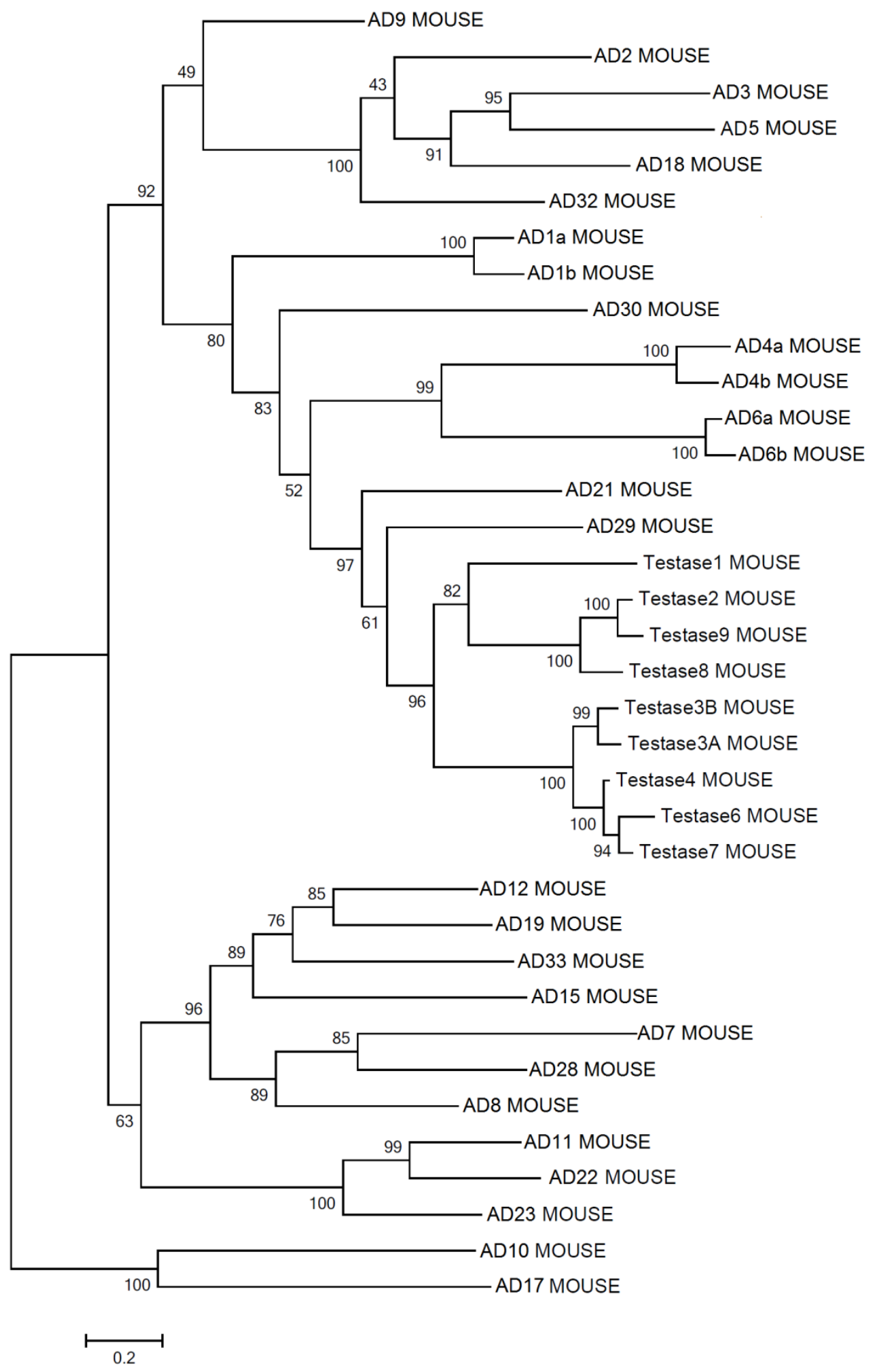

Figure 3: Maximum likelihood tree for mouse ADAMs. 


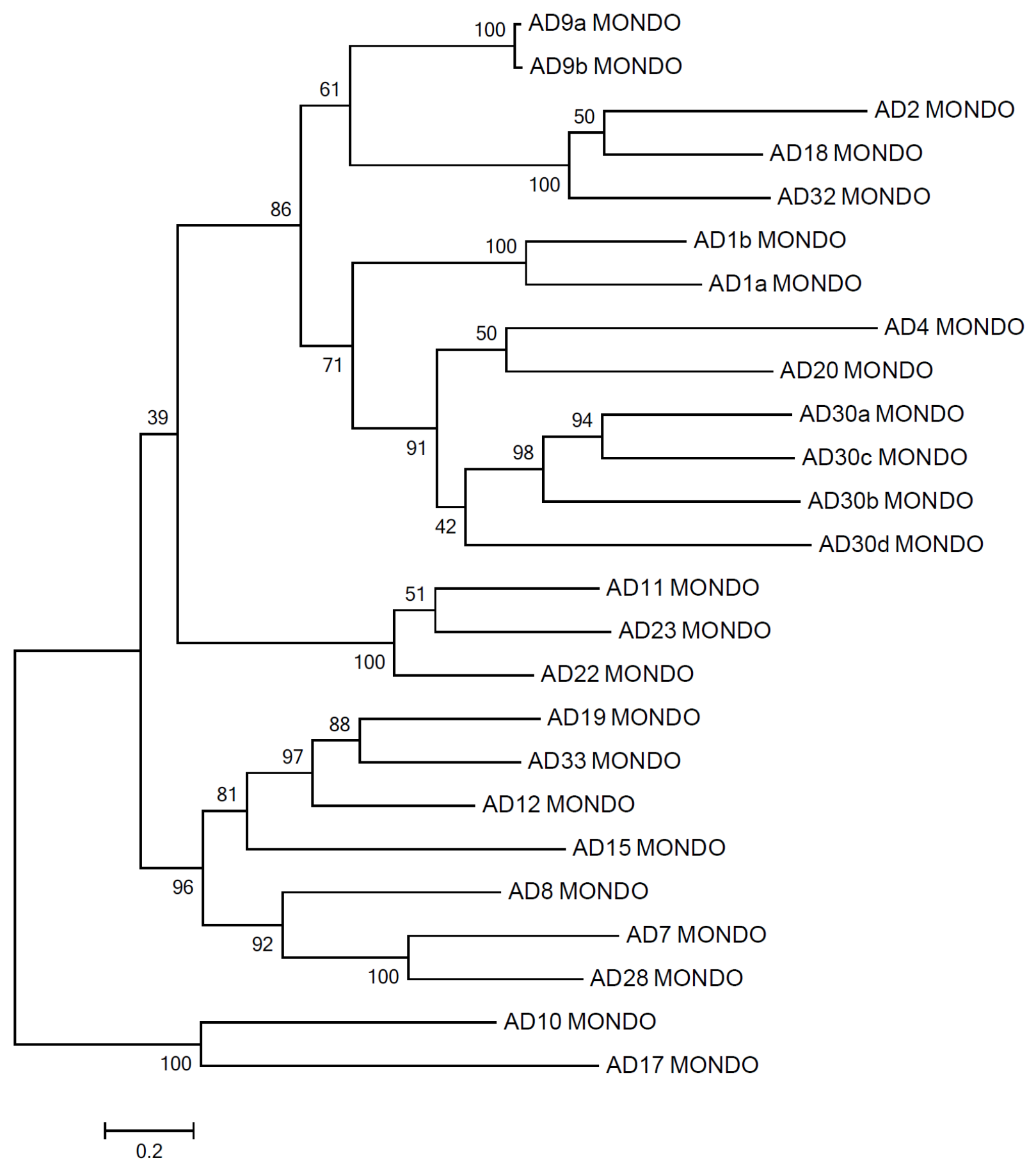

Figure 4: Maximum likelihood tree for opossum ADAMs. 


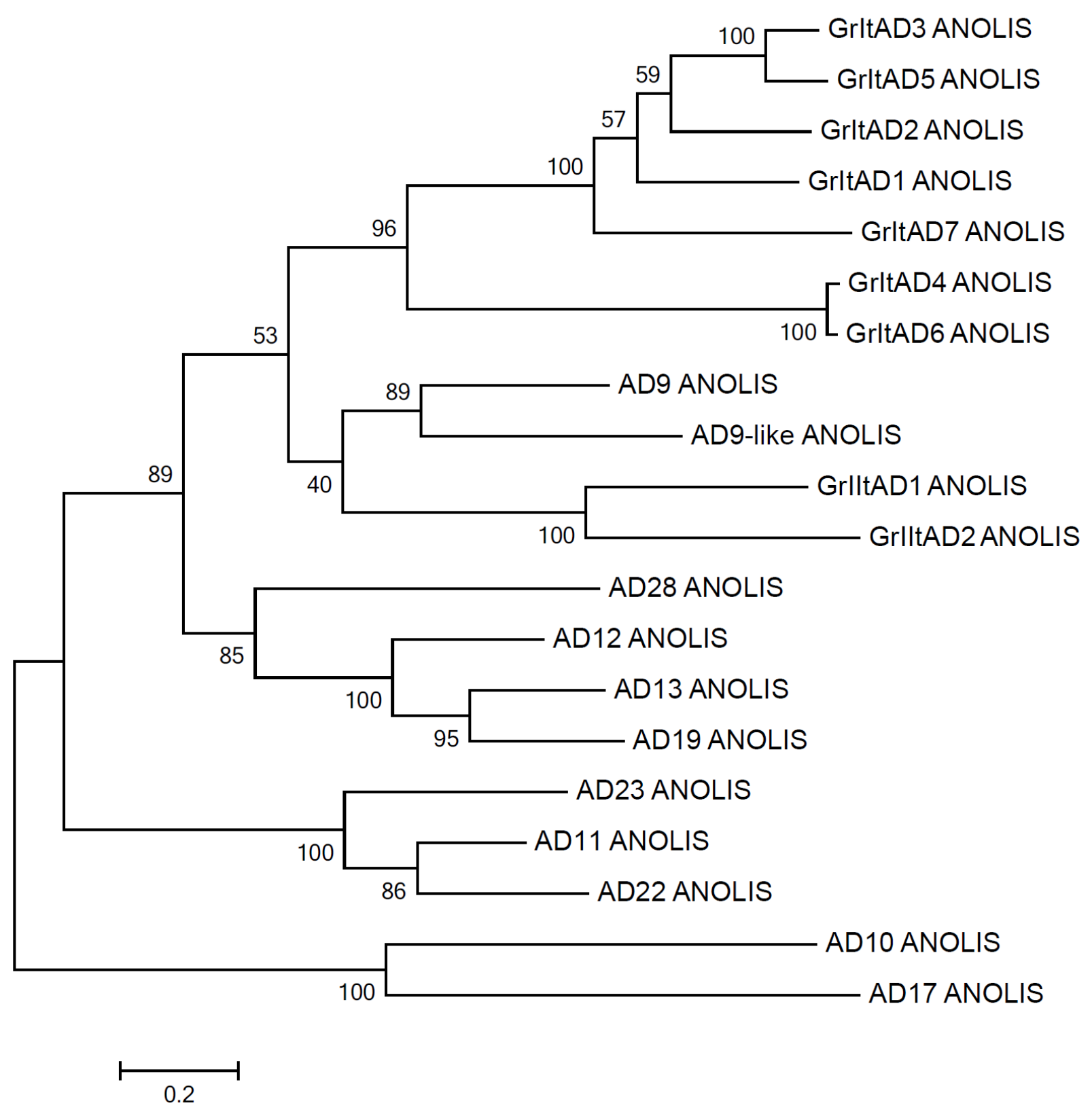

Figure 5: Maximum likelihood tree for lizard ADAMs. 


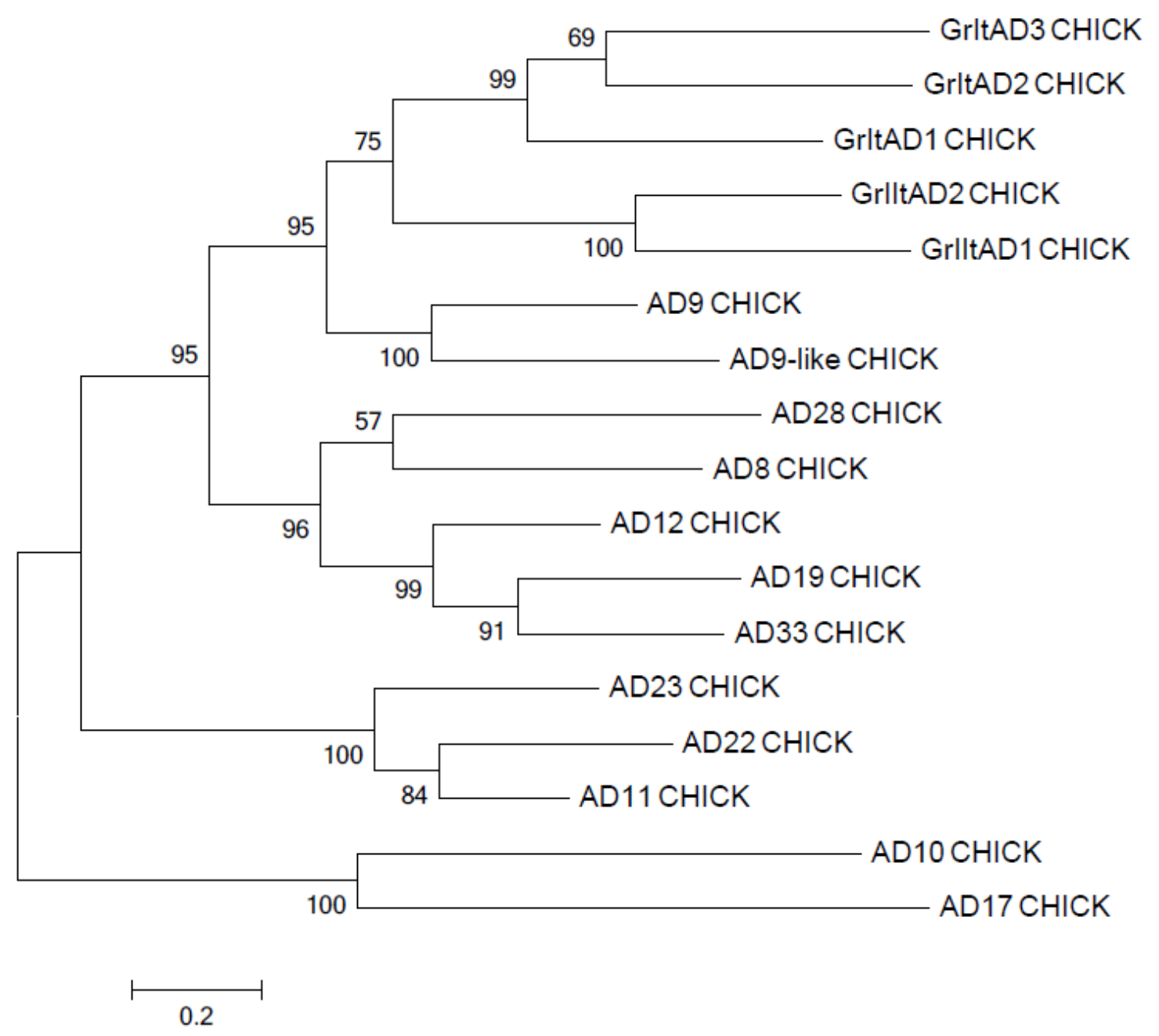

Figure 6: Maximum likelihood tree for chicken ADAMs. 


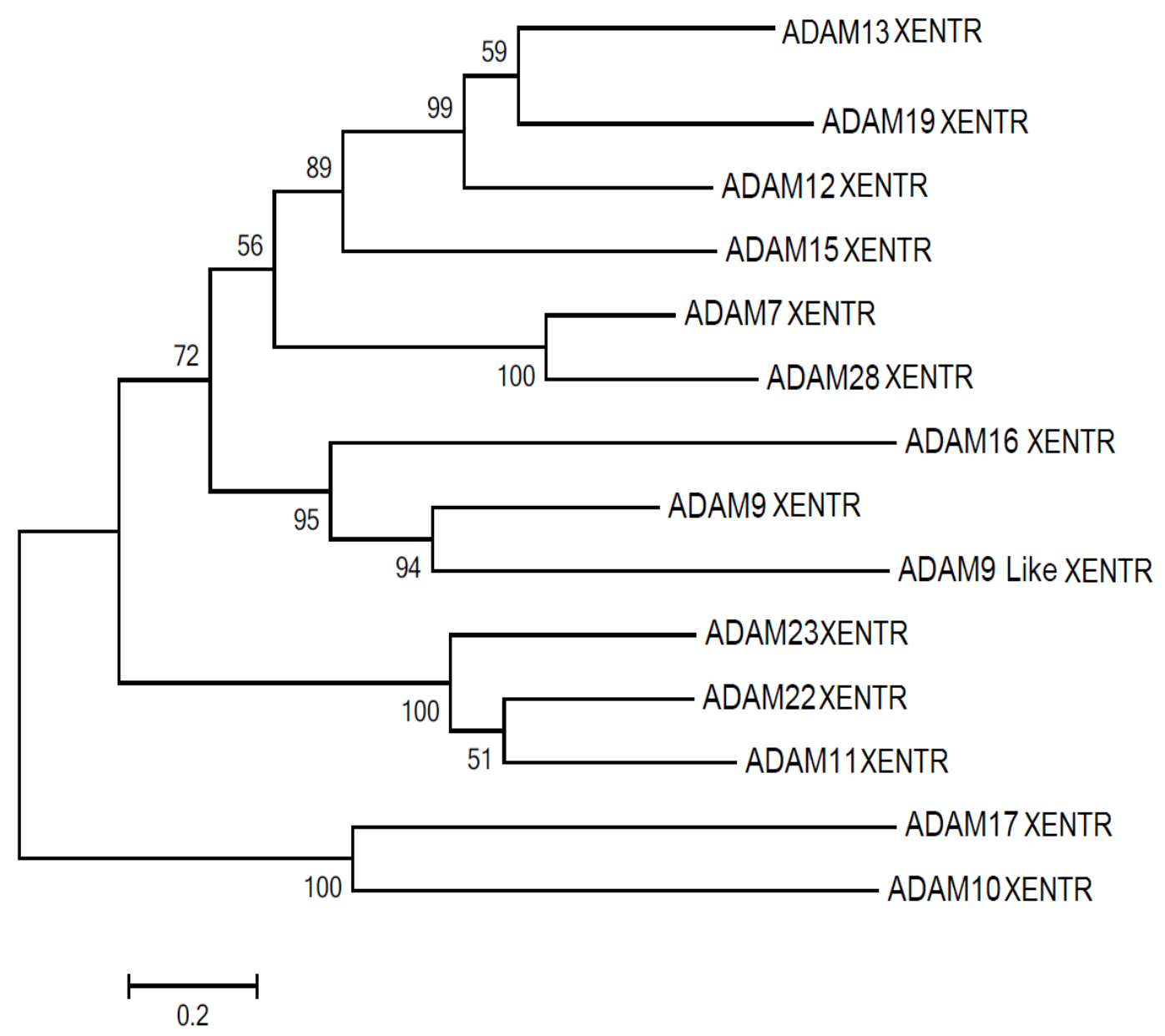

Figure 7: Maximum likelihood tree for frog ADAMs. 


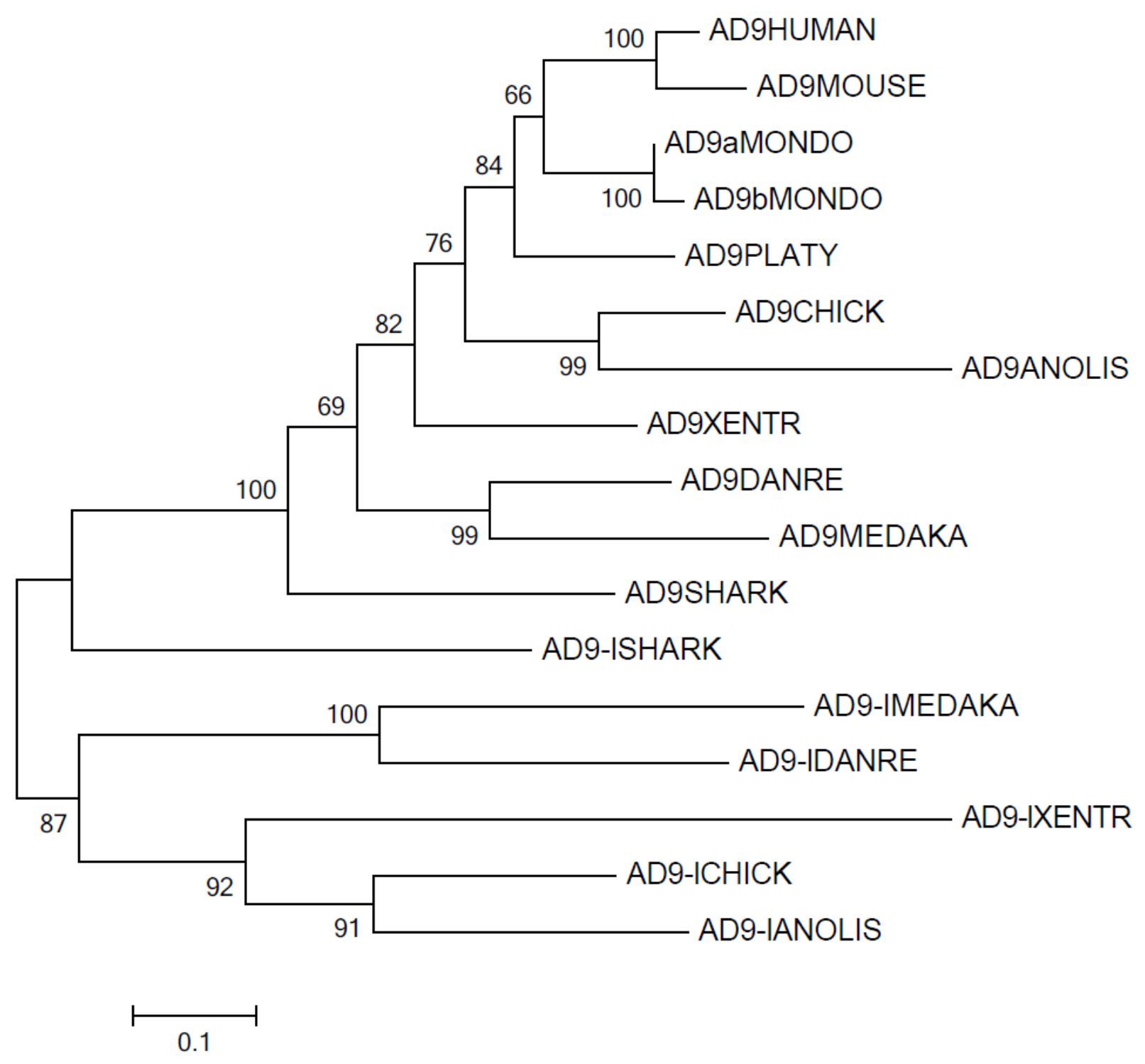

Figure 8: Maximum likelihood tree of ADAM9 for all tested vertebrates. 


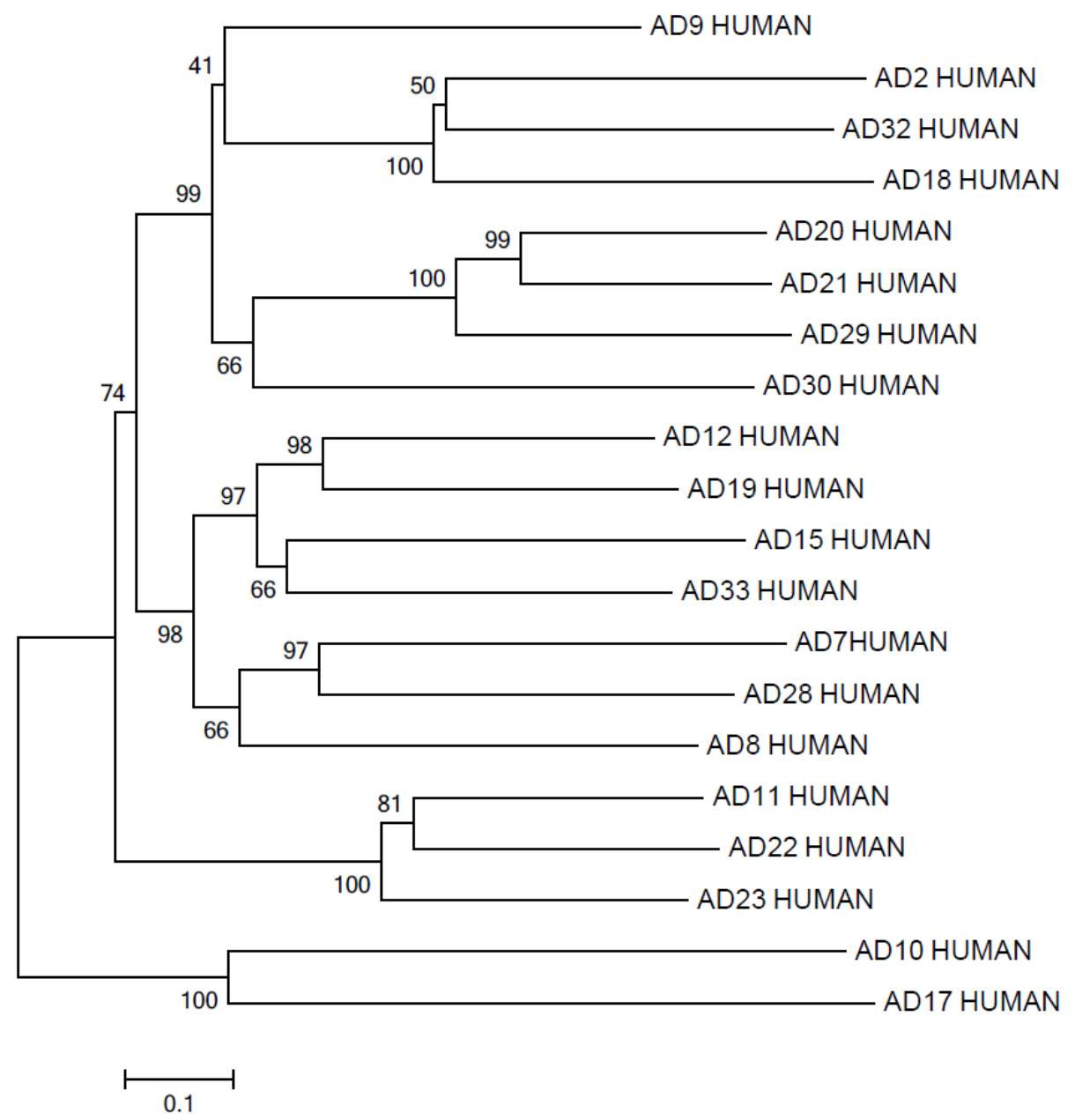

Figure 9: Neighbor joining tree for human ADAMs. 


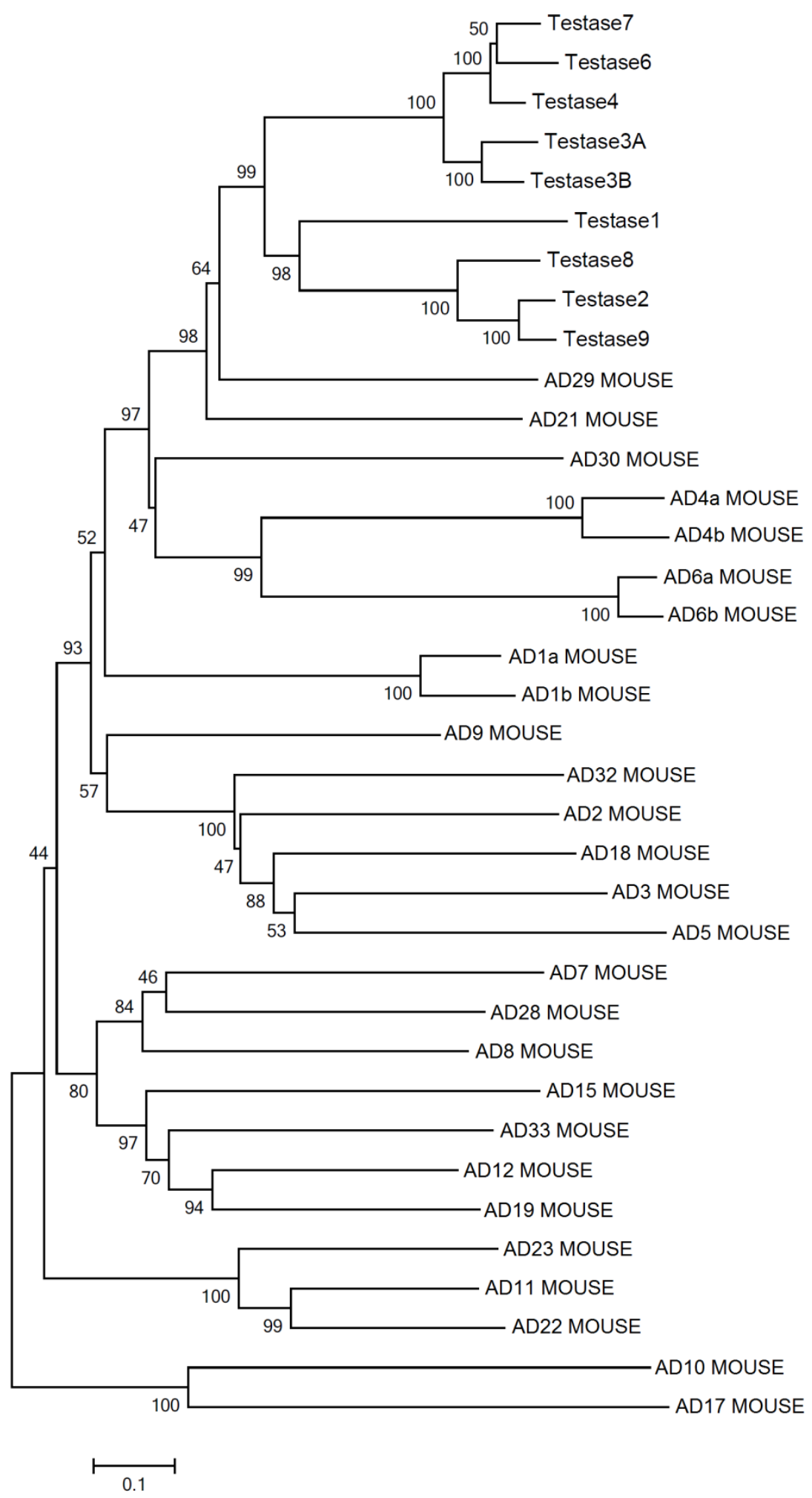

Figure 10: Neighbor joining tree for mouse ADAMs. 


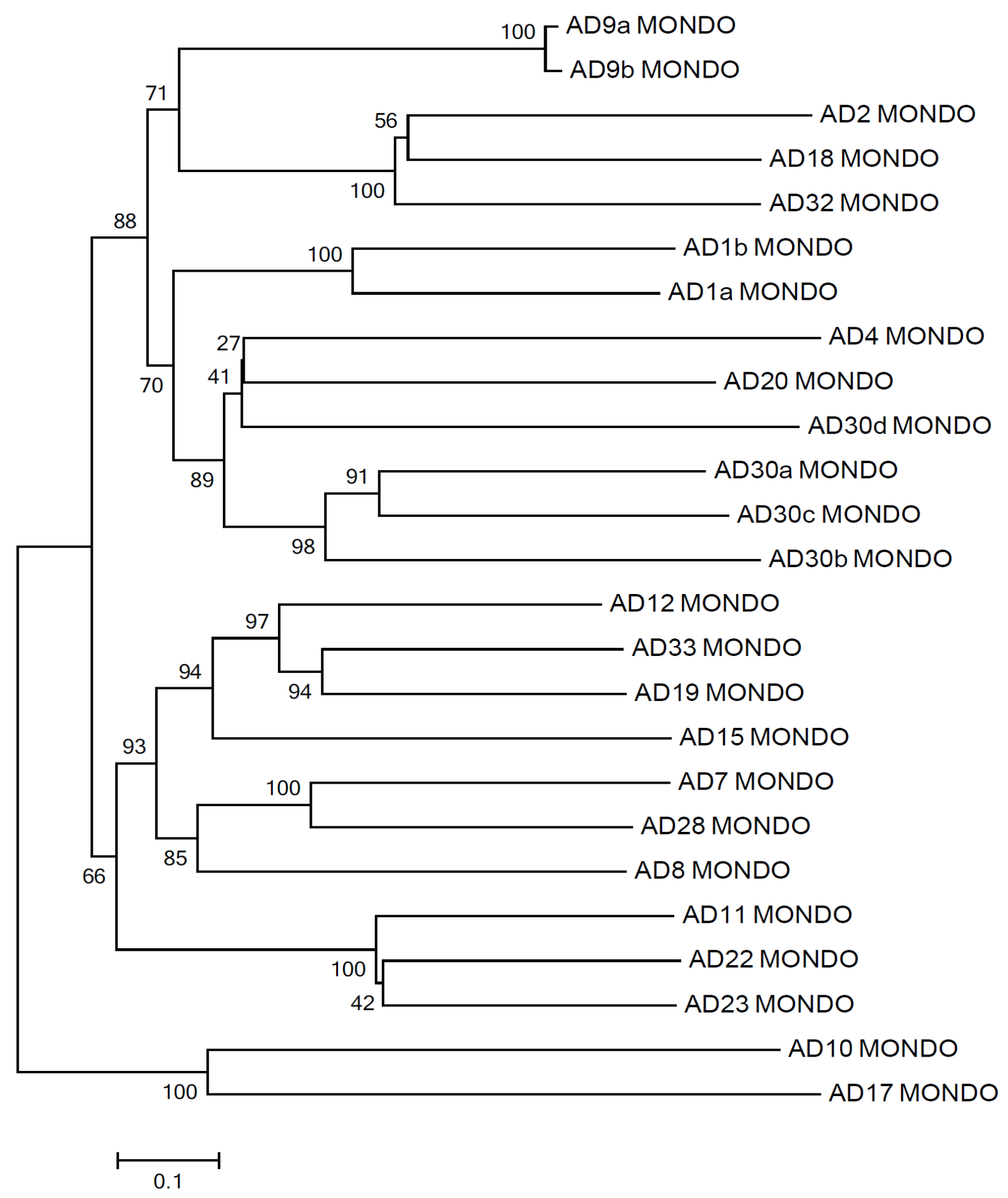

Figure 11: Neighbor joining tree for opossum ADAMs. 


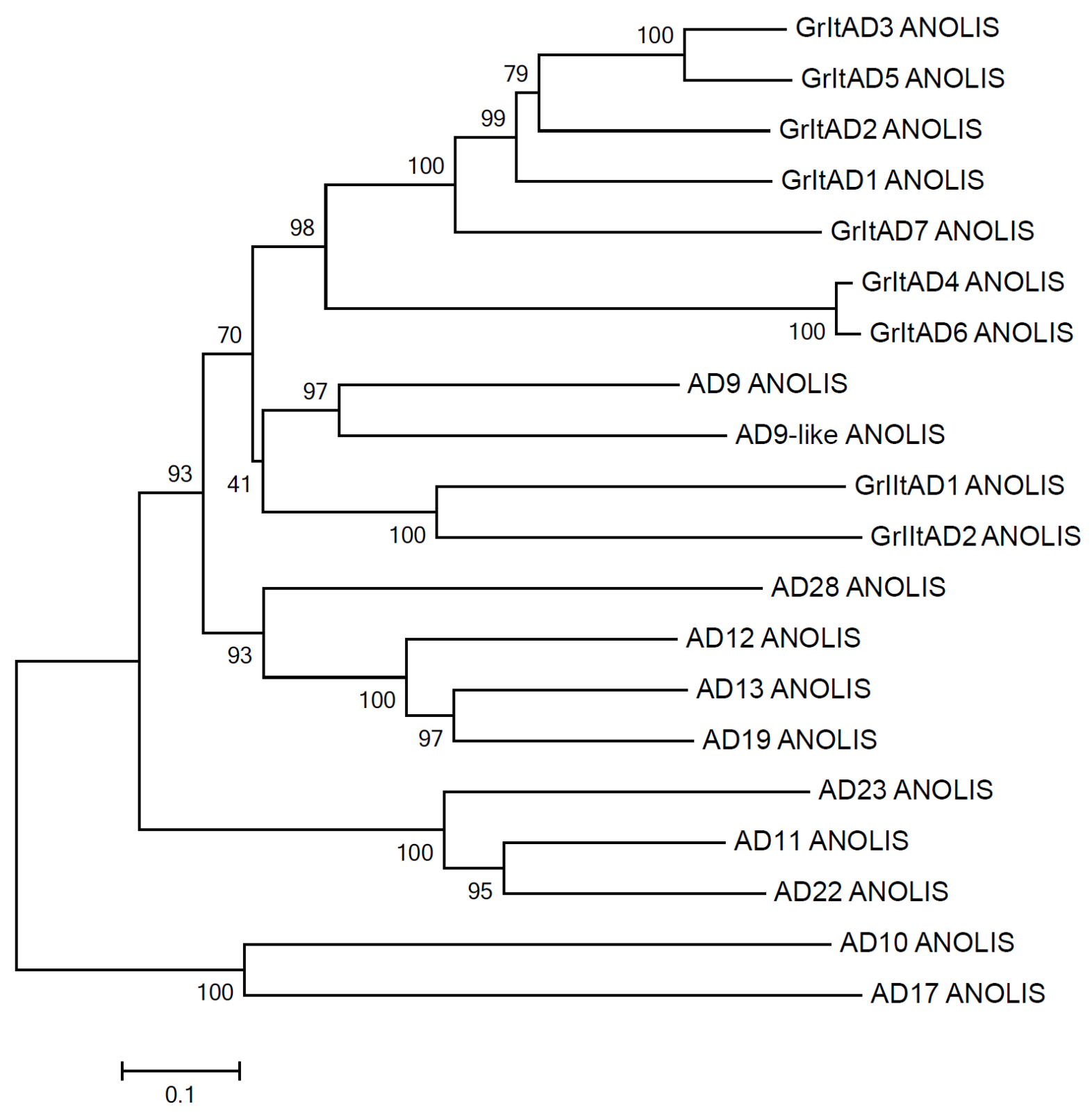

Figure 12: Neighbor joining tree for lizard ADAMs. 


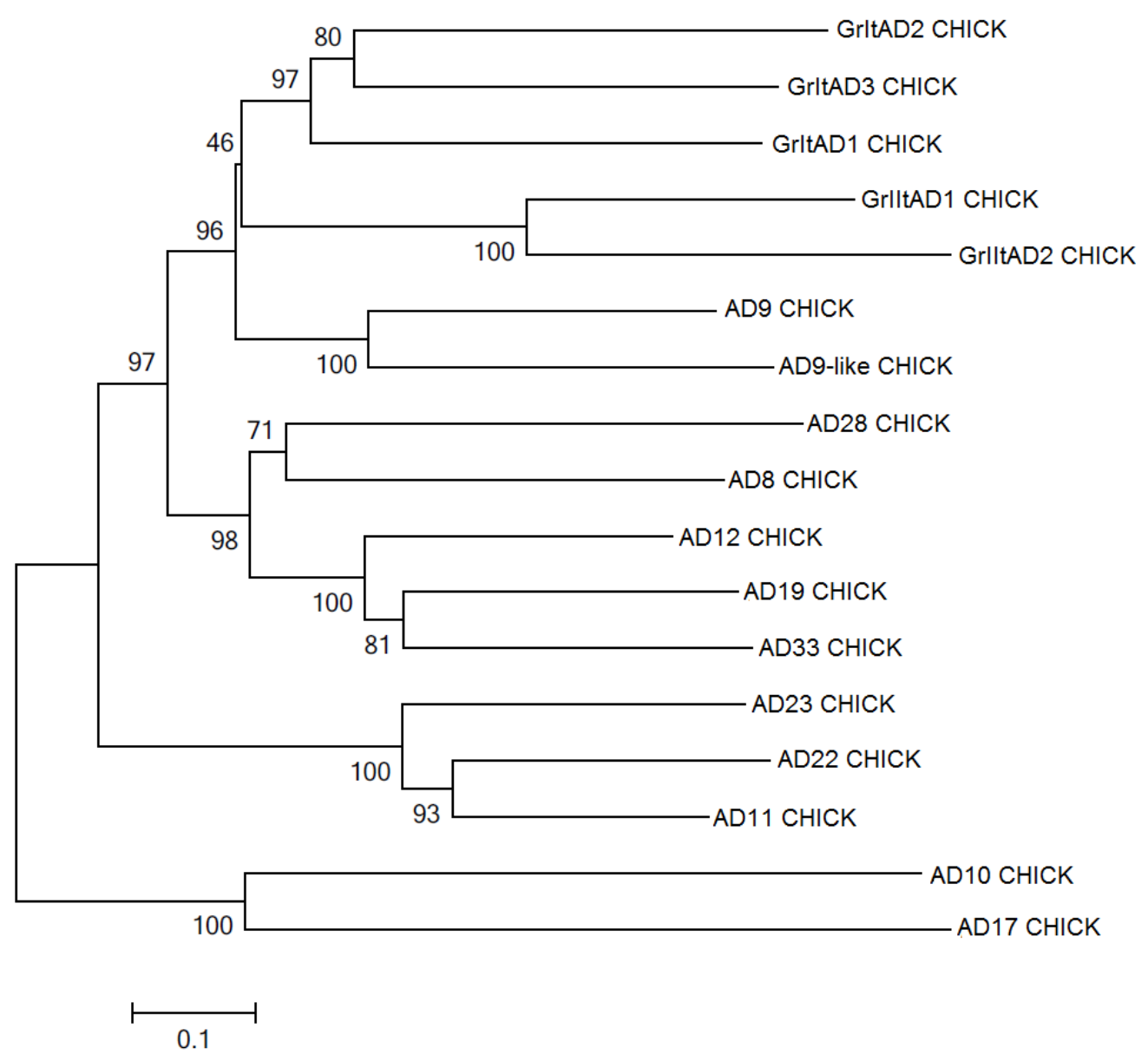

Figure 13: Neighbor joining tree for chicken ADAMs. 


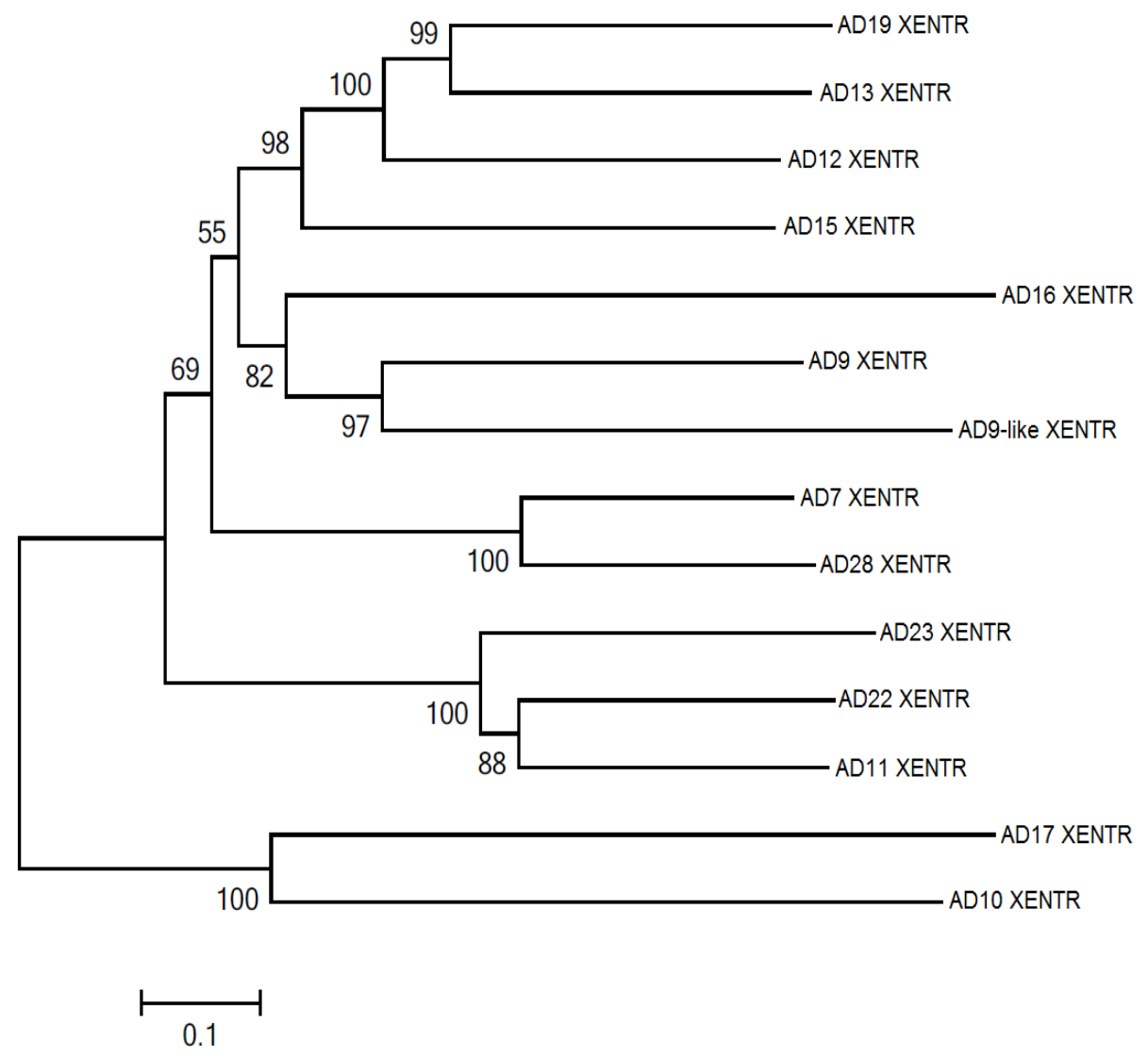

Figure 14: Neighbor joining tree for frog ADAMs. 


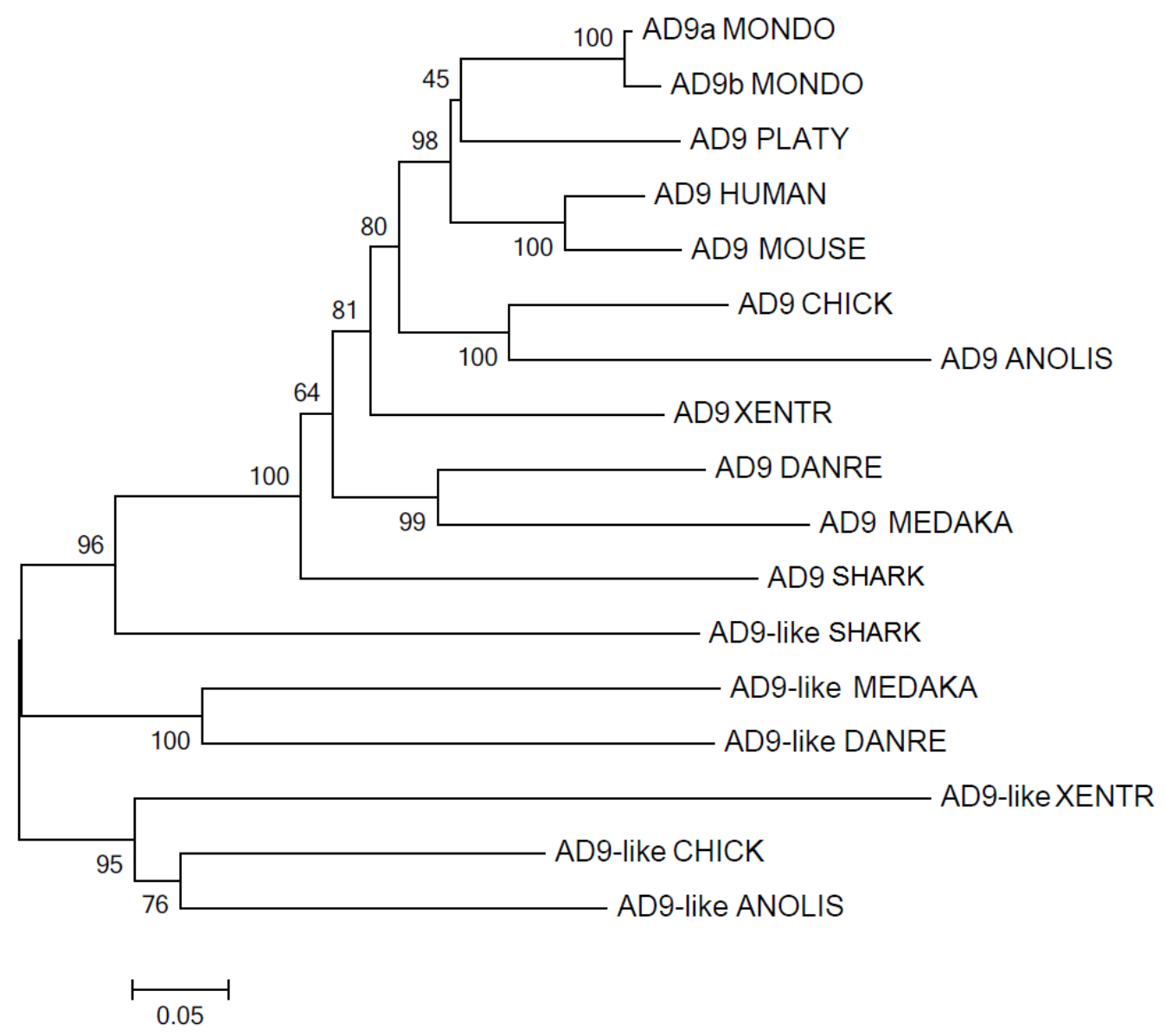

Figure 15: Neighbor joining tree of ADAM9 for all tested vertebrates. 